\title{
Unmasking the Effects of Orthography, Semantics, and Phonology on 2AFC Visual Word Perceptual Identification
}

\author{
Shaylyn Kress, Josh Neudorf, Chelsea Ekstrand \& Ron Borowsky \\ Department of Psychology, University of Saskatchewan
}

Word Count: 14121

\begin{abstract}
Author Note
This research was supported by the Natural Sciences and Engineering Research Council of Canada (NSERC) through Alexander Graham Bell Canada Graduate Scholarships to the lead author Shaylyn Kress, and to co-authors Josh Neudorf and Chelsea Ekstrand, and a Discovery Grant [18968-2013-21] to the senior author Ron Borowsky. The authors have no competing interests to declare.

Data Availability Statement: The data that support the findings of this study are openly available in Zenodo at https://doi.org/10.5281/zenodo.5296798, reference Kress et al. (2020).

Correspondence should be addressed to Ron Borowsky, Cognitive Neuroscience Lab, Department of Psychology, 9 Campus Drive, Saskatoon, SK, Canada, S7N 5A5. Email: ron.borowsky@usask.ca
\end{abstract}




\begin{abstract}
In the two-alternative forced-choice (2AFC) task, the target stimulus is presented very briefly, and the participants must choose between two options as to which was the presented target. Some past research (Grossi et al., 2009; Haro et al., 2019) has assumed that the 2AFC word identification task isolates orthographic effects, despite orthographic, semantic, and phonological differences between the alternative options. If so, performance should not differ between word target/nonword foil pairs and British/American word pairs, the latter of which only differ orthographically. In Experiment 1, accuracy and sensitivity were higher during word/nonword trials than British/American trials when participants stated their response was not a guess, demonstrating that phonological/semantic processing contributes to $2 \mathrm{AFC}$ performance. In Experiment 2, target visibility was manipulated by increasing the contrast between target and mask for half the trials. Experiment 2 showed that target visibility did not interact with pair type on reaction time, which suggests phonological/semantic processing did not result in feedback to orthographic encoding in this task. This study demonstrates the influence of phonological/semantic processing on word perceptual identification, and shows that $2 \mathrm{AFC}$ word identification does not isolate orthographic effects when word/nonword pairs are used, but using British/American word pairs provides a method for doing so. Implications for models and future research are discussed.
\end{abstract}

Keywords: word perception, orthography, phonology, semantics, two-alternative forcedchoice 


\section{Unmasking the Effects of Orthography, Semantics, and Phonology on 2AFC Visual Word Perceptual Identification}

Correctly identifying briefly presented words under sub-optimal conditions is a common experience (such as viewing items flashed on a screen during a video game, or quickly reading signs while driving), and it reflects a complex process. The question of whether this complexity includes feedback to the encoding level from higher levels has been explored as part of the modularity hypothesis (e.g., Fodor, 1983), which assumes that in order for perception to be accurate (i.e., veridical), encoding and representation systems should be modular and involve feed-forward activation only. Understanding relationships between these word representation systems is an important topic for many researchers, including those interested in general visual word processing (e.g., Scaltritti \& Balota, 2013; Aschenbrenner et al., 2017) and well as researchers studying bilingualism, where investigations of the word processing systems can help determine how second language learners process words in their non-native language (e.g., Grossi et al., 2009). Some reading models will implement interactive mechanisms between some systems, rather than implementing exclusively feed-forward activation. For example, the distributed memory model of word identification (Figure 1; Borowsky \& Masson, 1996; Masson \& Borowsky, 1998) outlines a neural network of the semantic (i.e., word meaning), phonological (i.e., pronunciation), and orthographic (i.e., spelling) representation systems. In this model, the orthographic system is where visual encoding occurs, and is responsible for the identification of letters that make up a word and their positional organization. From there, the information is passed to the higher levels of semantic and phonological units in a feedforward manner for processing of word meaning and pronunciation. These higher-level systems are interactive and can share activation with one another, thus affecting the production of output (e.g., speech or 
lexical decision; see Borowsky \& Masson, 1996; and Masson \& Borowsky, 1998, for further discussion of modularity in word identification). ${ }^{1}$

\section{Figure 1}

\section{Distributed-memory model of reading}

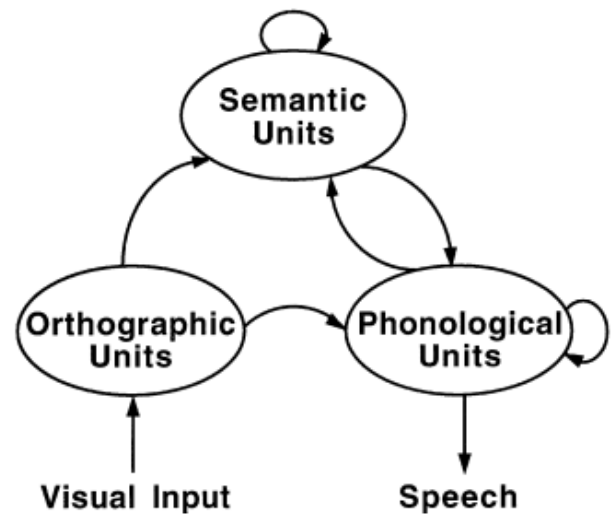

Note. Reprinted by permission from Springer Nature Customer Service Centre: Springer Nature Memory and Cognition, More than meets the eye: Context effects in word identification, Masson \& Borowsky (1998).

The Dual Route Cascaded model (DRC; see Coltheart et al., 2001) is another language processing model that focuses on word naming. In this model, three different routes are available to process words into speech. The first route is the grapheme-phoneme rule system, which maps letter forms directly to their corresponding pronunciation in a feedforward manner. The other two routes map the orthographic lexicon to the phonological lexicon, either with or without the involvement of the semantic system, with interactive relationships between these three systems.

\footnotetext{
${ }^{1}$ Consciousness studies have also relied on word stimuli (e.g., Marcel, 1983), but there has been little investigation regarding how the word representation units of semantics, phonology, and orthography may work together to aid in letter-string discrimination (see Lorentz et al., 2015 and 2016, for discussion of these issues and some research into this issue in the context of the Stroop task).
} 
The Connectionist Dual Process model (CDP++; see Perry et al., 2010, 2013) is a more recent model which also describes a combination of feedforward and interactive mechanisms working together to process visual word stimuli through either a lexical or sublexical network and produce phonological output. In the $\mathrm{CDP}++$ model, the sublexical network is described as feedforward and maps the letters directly to their corresponding sounds, while the lexical network includes interactive relationships between visual letter representations, an orthographic lexicon, and a phonological lexicon with optional semantics (see Wingerak et al., 2017 for a comparison between the DRC and earlier CDP+ models).

Recent research on these word representation systems has found evidence supporting the interactive relationships between orthography, phonology, and semantics, whereby consistency between orthographic (or phonological) forms and semantic meanings is predictive of performance in word processing tasks (such as in lexical decision; see Amenta et al., 2017; or Marelli \& Amenta, 2018). In lexical decision tasks, the role of feedback mechanisms has also been examined (e.g., Yap et al., 2015), but research into the feedforward versus feedback or distributed nature of processing in the two-alternative forced-choice (2AFC) paradigm has been limited.

\section{Two-Alternative Forced-Choice and the Isolation of Orthography}

The 2AFC task has historically been popular for examining the cognitive processes involved at low levels of conscious awareness. This task involves a target (e.g., a word or letterstring) being presented for a very brief period of time, and once this target stimulus disappears, participants must select which of two probes was the target that appeared. As described by Masson \& Borowsky (1998), a participant compares whatever partial information they have in memory from the target with the full encoding of the clearly presented probe 
stimuli. The pattern of activation from the probe that is most similar to that in memory from the target would be the chosen alternative. Some language processing research involving the $2 \mathrm{AFC}$ task has assumed that the task isolates the encoding of orthography (e.g., Grossi et al., 2009; Haro et al., 2019).

Grossi et al. (2009) refer to the word superiority effect and pseudoword (i.e., legal nonword, e.g., LAPE) superiority effect in word identification tasks, such as lexical decision or 2AFC, whereby word stimuli exhibit better performance than legal nonwords, which exhibit better performance than illegal nonwords (e.g., GLWK). Theories regarding the word superiority effect focus on the idea that orthographic regularities of real words boost performance, because the regular letter patterns are more familiar and easier to process. The researchers tested monolingual English speakers and bilingual Italian-English speakers with the Reicher-Wheeler variant $^{2}$ of $2 \mathrm{AFC}$ task in both English and Italian to evaluate whether the word superiority effect remained consistent, even for the participants' second language. For example, in the English word condition, participants were presented with a real word such as $\mathrm{P} \underline{\mathrm{ORCH}}$ and then identified which of two letters (e.g., O or E) appeared in the critical second position. The incorrect choice, 'E', spells a different real word, $\mathrm{PERCH}$, which differs semantically and phonologically from the presented word $\mathrm{P} \underline{\mathrm{ORCH}}$, thus allowing semantic and phonological differences to also aid identification. Grossi et al. (2009) observed word superiority effects in both Italian and English for the bilingual participants, but only in English for the monolingual participants. The researchers conclude these results supported their hypothesis that second language learners develop familiarity to the orthographic regularities of the second language. However, it is

\footnotetext{
2 The Reicher-Wheeler paradigm instructs participants to identify which of two letters appeared at the target location of the briefly presented stimulus (Reicher, 1969; Wheeler, 1970; Grainger et al., 2003).
} 
important to consider alternative explanations, such as the possible influence of the other word representation systems (i.e., semantics and phonology), because the observed superiority effects could be accounted for through a familiarity-activation monitoring process of the activation of all three of orthography, semantics, and phonology (e.g., Borowsky \& Masson, 1996; Masson \& Borowsky, 1998).

In Haro et al.'s study (2019), the researchers used the 2AFC task to compare theories regarding the identification advantage that exists for ambiguous words (words that have more than one meaning, e.g., "bank"). The researchers described the semantic feedback theory (Hino \& Lupker, 1996), which explains the ambiguous word advantage over unambiguous words in terms of the semantic information from the two meanings feeding back into orthography and boosting orthographic encoding. This semantic feedback theory was contrasted with the Borowsky and Masson (1996; Masson \& Borowsky, 1998) neural network model, which does not boost orthography by phonological/semantic feedback but produces an ambiguity advantage through monitoring activation in the network. Haro et al.'s (2019) results showed an advantage for identifying ambiguous words during the classic 2AFC task (e.g., "bank" is presented, then participants indicate whether the presented word was "bank" or "bunk"), and concluded that the semantic feedback hypothesis was the best theory to account for these results if isolation of the orthographic system in the $2 \mathrm{AFC}$ task is assumed. However, given that the alternatives also differ semantically and phonologically, orthographic isolation should not be assumed, and the results could be explained without such semantic feedback by simply monitoring activation of all three systems (Masson \& Borowsky, 1998). Some studies do not assume orthographic isolation when studying visual word processing effects with the $2 \mathrm{AFC}$ task and do evaluate whether semantics or phonology may be playing a role in the observed results (see Scaltritti \& Balota, 
2013; Ashenbrenner et al., 2017 for 2 AFC studies on the serial position effect in visual word processing).

\section{The Present Research}

The goal of this research using the $2 \mathrm{AFC}$ task is to evaluate the influence that orthography, semantics, and phonology may have on word perception, rather than assuming the task serves to isolate the contribution of orthography. Two experiments using the 2AFC task were used to test how the different representational systems influence word perception by comparing word/legal nonword pairs (cosy/comy) to British/American spelling variants (cosy/cozy). Canadian university students are an ideal sample for this research given their familiarity with both British and American English spellings. Word/nonword pairs differ on orthography, semantics, and phonology, so all three of the systems may contribute to discrimination performance. In comparison, the British/American spelling variants only differ orthographically in the form of either differences in letter units (e.g. "s" vs " $\mathrm{z}$ " in cosy/cozy) or differences in positional organization of the letter units (e.g. "re" vs "er" in centre/center). In British/American spelling variants there should be no difference in semantics and phonology to contribute to discrimination performance when the words are presented to a Canadian sample. The comparison of these two conditions allows us to see how differences in orthography, semantics and phonology (cosy/comy), versus just orthography (cosy/cozy), can affect performance in terms of not only accuracy/sensitivity, but also reaction time $(\mathrm{RT})^{3}$. This work will add to the sparse literature examining RT patterns in a $2 \mathrm{AFC}$ task (see Scaltritti \& Balota,

\footnotetext{
${ }^{3}$ It should be noted that the use of a word-nonword comparison is not a direct parallel to word superiority effect research, which avoids contrasting words to nonwords within a trial in order to avoid any lexical word bias (i.e., a bias for choosing the word alternative, particularly under conditions of uncertainty). We use the Word/Nonword pairs as a way to experimentally manipulate orthography, phonology, and semantic differences relative to the British/American word pairs.
} 
2013; Lorentz et al., 2015; Aschenbrenner et al., 2017; or Haro et al., 2019 for examples including the RT measure; see Grossi et al., 2009; Haase \& Fisk, 2011; or Manelis, 1974 for examples of its absence). Differing stimulus durations were included and subjective awareness levels recorded, given that past consciousness research has demonstrated that reading effects can be dependent on awareness level (see Lorentz et al., 2015). Varying the durations will accommodate the range of consciousness thresholds and avoid the risk of all responses falling into the undesirable zones of floor or ceiling accuracy.

\section{Summary and Hypotheses}

Given that researchers often assume that $2 \mathrm{AFC}$ tasks isolate orthographic processing (Grossi et al., 2009; Haro et al., 2019), Experiment 1 includes a condition with British/American word stimuli to help determine whether this assumption is justified. There are two main hypotheses for Experiment 1:

1. If the representations of orthography, semantics, and phonology all play a role in $2 \mathrm{AFC}$ performance, participants should be more accurate and may have faster RTs when choosing between word/nonword pairs because these pairs differ in orthography, semantics, and phonology (see Figure 2a). In contrast, the British/American spelling variants only differ on orthography, isolating the discriminating information to just a single system, which should lead to more errors in identification as well as slower RTs. If only orthography plays a role in $2 \mathrm{AFC}$ perceptual word identification, then there should be no differences as a function of pair type (British/American versus word/nonword; see Figure 2b). 


\section{Figure 2}

Hypothesized activation of word representation systems in $2 A F C$ if all three systems are activated (a) or only orthography is activated (b)
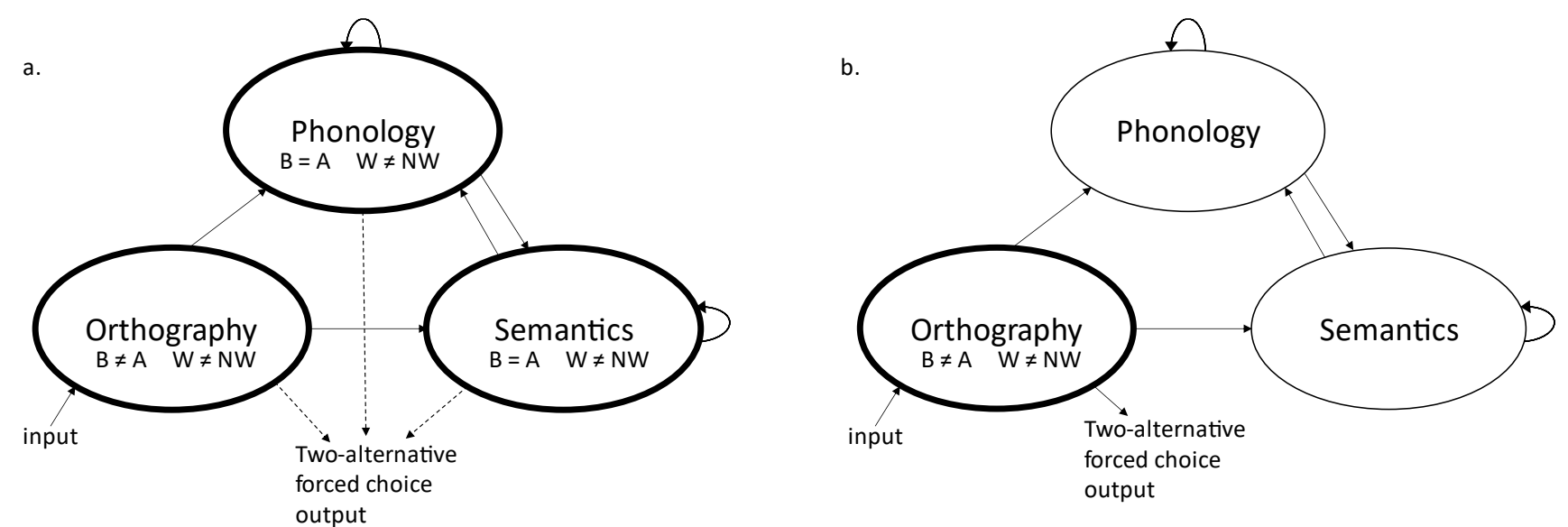

2. In terms of consciousness levels, subjective awareness of the stimuli should amplify (i.e., interact with) the effects of pair type and result in even higher accuracy (and faster RTs). If participants indicate that they guessed, then they are below the subjective threshold of awareness, and if their accuracy is at chance then they are at (or below) the objective threshold of awareness. 


\section{Experiment 1}

\section{Method}

\section{Participants}

Participants were recruited through the University of Saskatchewan Participant Pool or through an online bulletin posted on the campus website. Students recruited through the participant pool were given bonus course credit in exchange for their participation, and those recruited through the bulletin received \$5. Grossi et al. (2009) included 14 English speaking participants, and observed a difference of 5\% accuracy between the word and legal nonword conditions $\left(\eta^{2}=.28\right)$. We calculated that, for our study to detect a similar effect size in regards to pair type with a power of 0.8 at $p=0.05,24$ participants would be needed.

Twenty-four participants $(M=22.71$ years, $S E=0.92$ years, 18 to 38 years; 20 female, 4 male) took part in this study, and the first language of all participants was English. Canadian university students were considered ideal for this study as they encounter both British and American spellings in their reading materials, and are relatively familiar with both spellings. The participants' consent was obtained and the experiment was performed in compliance with the relevant laws and institutional guidelines, and was approved by the University of Saskatchewan Research Ethics Board.

\section{Apparatus}

The experimental task was programmed in E-Prime 2.0 (Psychology Software Tools, https://pstnet.com), and presented to participants on a Compaq 7500 CRT monitor with a refresh rate of $75 \mathrm{~Hz}$ (13.33 ms). A serial-response box was used to record participant responses and determine both accuracy and RT. 


\section{Stimuli}

The stimuli consisted of 20 British/American word pairs and their corresponding pronounceable nonwords (see Appendix A). The mean length of these words was $6.05(S D=$ $1.68, \min =3, \max =9)$, mean $\log H A L$ frequency was $7.80(S D=1.94, \min =3.83, \max =11.59)$ and mean number of orthographic neighbours was $3.95(S D=4.646, \min =0, \max =18)$ according to the English Lexicon Project (Balota et al., 2007). Summed bigram frequencies did not significantly differ between the British and American words, $t(38)=1.05, p=0.301$. Nonwords were constructed by changing one letter of the real words to create a pronounceable but semantically meaningless letter-string. For the majority of stimuli, this was achieved by replacing the letter in the position that distinguishes the British and American variants (e.g. for cosy/cozy, the nonword becomes "comy"). If it was not possible to create a pronounceable letter string with this constraint, or the only pronounceable options spelled or sounded like a real word, then a different letter was chosen for replacement. For words of the "er"/"re" family (e.g. centre/center), to ensure that the nonwords were one-letter different from the corresponding real word, the "er"/"re" of the word was preserved, and a different letter was replaced. Summed bigram frequencies did not significantly differ between British words and the corresponding nonwords, $t(38)=-0.46, p=0.650$, and did not differ between American words and the corresponding nonwords, $t(38)=-0.275, p=0.785$.

The stimuli appeared for a variable duration that is near the threshold of consciousness (27ms, 40ms, or 53ms) to compare both conscious and subconscious levels of performance (Cheesman \& Merikle, 1986; Lorentz et al., 2015). Stimuli were presented in white text (Courier New, size 18 font) on a black background. In the British/American block, there were 40 trials per duration (one trial where the British word was the target, and one trial where the American word 
was the target for each British/American pair), for a total of 120 trials. The word/nonword block also had 40 trials per duration (one trial where a word was the target, and one trial where the nonword was the target for each word/nonword set), for a total of 120 trials. In the word/nonword block, participants would see the British spelling for two of the three durations or the American spelling for two of the three durations, but when participant trials are combined, the distribution of British and American spellings at each duration is equal (see Appendix B for the counterbalance procedure). The order of the British/American trial block and word/nonword trial block were counterbalanced, with half of the participants receiving the British/American block first. The order of trials within each block was randomized.

\section{Procedure}

The experiment took place in a dimly lit, quiet room. Participants were tested individually, and a researcher was present with the participant for the duration of the experiment. After providing informed consent, each trial proceeded as follows (see Figure 3): A fixation cross would appear onscreen and participants would press the far left and far right buttons simultaneously on the serial-response box to begin each trial. The screen was then black for 500ms. A string of hash symbols (12 characters long) appeared as a pre-mask for $53 \mathrm{~ms}$, the target word or letter-string was then presented for one of the three target durations, followed by a post-mask which was identical to the pre-mask. The screen was then black for approximately 50 ms before the forced-choice probes appeared. Participants used the left and right buttons on the serial-response box to make their choice (corresponding to the option on the left and the option on the right, respectively). The appearance of each choice on the left or the right side was randomized. After making their choice, the screen was then black for another $250 \mathrm{~ms}$ before the awareness check appeared. For the awareness check, participants responded to the yes-no 
question, “Did you feel like you were guessing?". Participants pressed the left button if they did not guess and pressed the right button if they did guess. Upon completing the experiment, participants were debriefed, and provided with the opportunity to ask questions about the study.

\section{Figure 3}

Experiment 1 Trial Progression
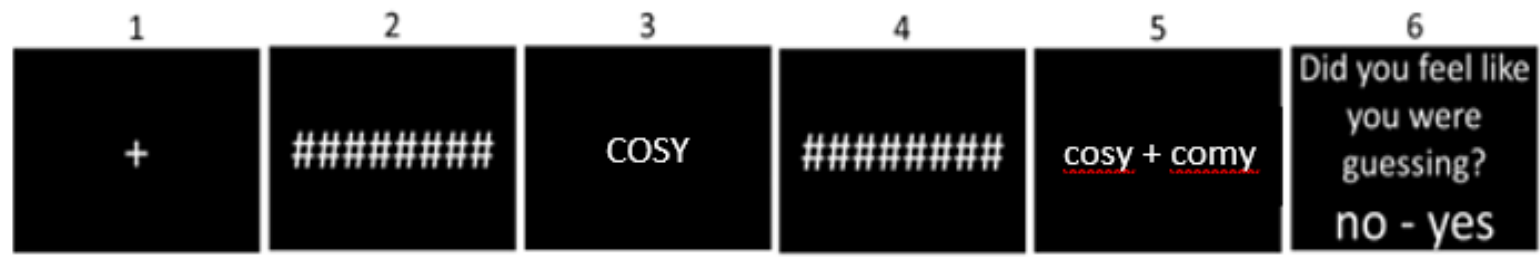

Note. Trial progression from: (1) fixation cross, to (2) pre-mask for $53 \mathrm{~ms}$, to (3) target for either

$27 \mathrm{~ms}, 40 \mathrm{~ms}$, or $53 \mathrm{~ms}$, to (4) post-mask for $53 \mathrm{~ms}$, to (5) $50 \mathrm{~ms}$ blank screen followed by the 2AFC probes, to (6) subjective threshold assessment. 


\section{Results}

Six of the 24 participants guessed during all $27 \mathrm{~ms}$ trials in either the British/American or word/nonword block, and two of these six guessed for all $27 \mathrm{~ms}$ trials in both blocks. Therefore, the $27 \mathrm{~ms}$ trials were excluded from the primary analysis for all participants, as this tendency to guess suggests that $27 \mathrm{~ms}$ was too difficult for many of the participants and would leave too many empty cells of data. One participant's accuracy was zero when guessing during the British/American condition, which meant there were no correct trials to measure the participant's reaction time for this condition. Due to the lack of reaction time data, this participant was excluded from analysis, so all analyses were conducted with the remaining 23 participants. Table 1 summarizes the proportion of Aware responses for the different conditions in Experiment 1.

\section{Table 1}

Proportion of Aware responses for the different Experiment 1 conditions

\begin{tabular}{lllr}
\hline & \multicolumn{2}{l}{ Proportion } & \multicolumn{1}{c}{ Durations Combined } \\
\cline { 2 - 3 } Condition & & All Trials (Correct Trials only) & All Trials (Correct Trials only) \\
\hline British/American & $40 \mathrm{~ms}$ & $0.42(0.47)$ & $0.49(0.54)$ \\
\cline { 2 - 3 } & $53 \mathrm{~ms}$ & $0.55(0.60)$ & \\
\hline Word/Nonword & $40 \mathrm{~ms}$ & $0.41(0.50)$ & $0.50(0.59)$ \\
& & & \\
\cline { 2 - 3 } & $53 \mathrm{~ms}$ & $0.60(0.68)$ & \\
\hline
\end{tabular}


Based on the results of an initial 2 (Pair Type: British/American vs Word/Nonword) $\times 2$ (Subjective Awareness: Unaware vs Aware) $\times 2$ (Duration: 40ms vs 53ms) repeated measures ANOVA, there was no effect of Duration on accuracy, $F_{S}(1,22)=2.909, p=.102, \eta_{p}{ }^{2}=.117$ or reaction time, $F_{S}(1,22)=.474, p=.498, \eta_{p}{ }^{2}=.021$. Therefore, the subsequent analyses pool the two durations ${ }^{4}$.

As shown by Wingerak et al. (2017), Linear Mixed Model (LMM) analyses are not a panacea for replacing by-subjects and by-items analyses, as each type of analysis provides an important perspective on what the results can generalize to. The following sections report the 2 (Pair Type: British/American vs Word/Nonword) × 2 (Subjective Awareness: Unaware vs Aware) repeated measures ANOVA results, and the supplementary General Linear Mixed Model (GLMM) and LMM results can be found in Appendix C. We focus our interpretation on results that are consistent across the multiple analysis techniques.

\section{Accuracy}

We used one sample t-tests to evaluate whether accuracy was significantly above chance for the different condition types. These one sample t-tests showed that during unaware trials, participant accuracy was at chance levels, whereas when participants were aware of the stimuli, their accuracy was significantly above chance ( 0.5 indicates chance performance; see Table 2$)$.

\footnotetext{
${ }^{4}$ Accuracy was analysed for effects of repetition, given the repeated presentation of targets and probe pairs. Repetition of probe pairs was found to not significantly interact with our manipulation of pair type. Trials from all 3 durations $(27 \mathrm{~ms}, 40 \mathrm{~ms}$, and $53 \mathrm{~ms})$ were included for the analysis of repetition effects. In a 2 (Pair Type: B/A vs $\mathrm{W} / \mathrm{NW}) \times 6$ (Occurrence) repeated measures ANOVA, there was no main effect of Occurrence on Accuracy, $F(5$, $110)=0.44, p=.819, \eta_{p}{ }^{2}=.02$. The main effect of Pair Type is significant, $F(1,22)=6.71, p=.017, \eta_{p}{ }^{2}=.23$. The interaction between Pair Type and Occurrence on Accuracy was not significant, $F(5,110)=1.09, p=.369, \eta_{p}{ }^{2}=$ .05 .
} 


\section{Table 2}

Accuracy as a function of Pair Type and Subjective Awareness Level

\begin{tabular}{|c|c|c|c|c|c|}
\hline \multicolumn{4}{|l|}{ By-Subjects } & \multicolumn{2}{|c|}{ Difference from Chance } \\
\hline & Subjective & & & & \\
\hline Pair Type & Awareness & $M$ & $S E$ & $t(22)$ & $p$ \\
\hline \multirow[t]{2}{*}{ British/American } & Unaware & 0.53 & 0.02 & 1.94 & .066 \\
\hline & Aware & 0.69 & 0.03 & 7.75 & $<.001$ \\
\hline \multirow[t]{2}{*}{ Word/ Nonword } & Unaware & 0.52 & 0.02 & 1.03 & .316 \\
\hline & Aware & 0.77 & 0.02 & 12.49 & $<.001$ \\
\hline \multirow[t]{2}{*}{ By-Items } & & & & \multicolumn{2}{|c|}{ Difference from Chance } \\
\hline & \multicolumn{3}{|l|}{ Subjective } & & \\
\hline Pair Type & Awareness & M & SE & $t(19)$ & $p$ \\
\hline \multirow[t]{2}{*}{ British/ American } & Unaware & 0.54 & 0.01 & 2.93 & .009 \\
\hline & Aware & 0.64 & 0.02 & 6.24 & $<.001$ \\
\hline \multirow[t]{2}{*}{ Word/ Nonword } & Unaware & 0.54 & 0.02 & 2.05 & .055 \\
\hline & Aware & 0.72 & 0.03 & 7.33 & $<.001$ \\
\hline
\end{tabular}

According to the 2 (Pair Type: British/American vs Word/Nonword) $\times 2$ (Subjective Awareness: Unaware vs Aware) repeated measures ANOVA, there was a significant main effect of subjective awareness on accuracy by-subjects and by-items, whereby participant accuracy was lower when unaware of the stimuli $\left(M_{S}=0.53, S E_{S}=0.01 ; M_{I}=0.54, S E_{I}=0.01\right)$, than when aware $\left(M_{S}=0.73, S E_{S}=0.02 ; M_{I}=0.68, S E_{I}=0.02\right)$. There was a significant interaction between pair type and subjective awareness by-subjects, and by-items, but the main effect of pair type only approached significance (see Table 3 for a summary of these results). 


\section{Table 3}

Summary of Accuracy ANOVAs

\begin{tabular}{lrrrr}
\hline By-Subjects & & & & \\
& $F(1,22)$ & $M S E$ & $p$ & $\eta_{p}{ }^{2}$ \\
\hline Subjective Awareness & 100.49 & 0.009 & $<.001$ & 0.82 \\
Pair Type & 3.45 & 0.006 & .077 & 0.14 \\
Subjective Awareness x Pair Type & 8.46 & 0.006 & .008 & 0.28 \\
\hline By-Items & & & & \\
& $F(1,19)$ & $M S E$ & $p$ & $\eta_{p}{ }^{2}$ \\
\hline Subjective Awareness & 41.86 & 0.01 & $<.001$ & 0.69 \\
Pair Type & 3.18 & 0.01 & 0.09 & 0.14 \\
Subjective Awareness x Pair Type & 9.51 & 0.003 & 0.006 & 0.33 \\
\hline
\end{tabular}

An analysis of $95 \%$ Confidence Intervals (CIs) was conducted to assess the interaction between pair type and subjective awareness. The 95\% CIs (see Loftus \& Masson, 1994) suggest that when participants are unaware of the stimuli, accuracy is no different between the word/nonword condition and the British/American condition, but when participants are aware of the stimuli presented, accuracy is significantly higher in the word/nonword condition than in the British/American condition (see Figure 4). 


\section{Figure 4}

Accuracy as a function of Pair Type and Subjective Awareness, By-Subjects (a) and By-Items (b)

a.

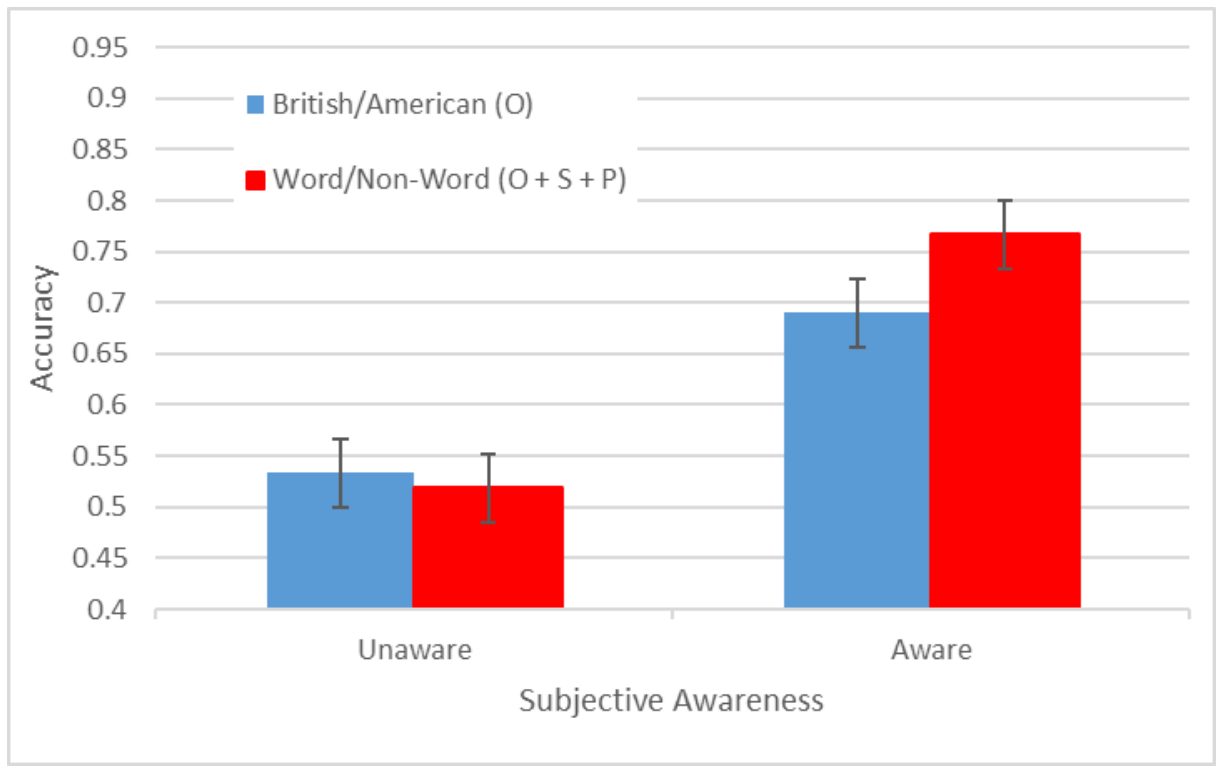

b.

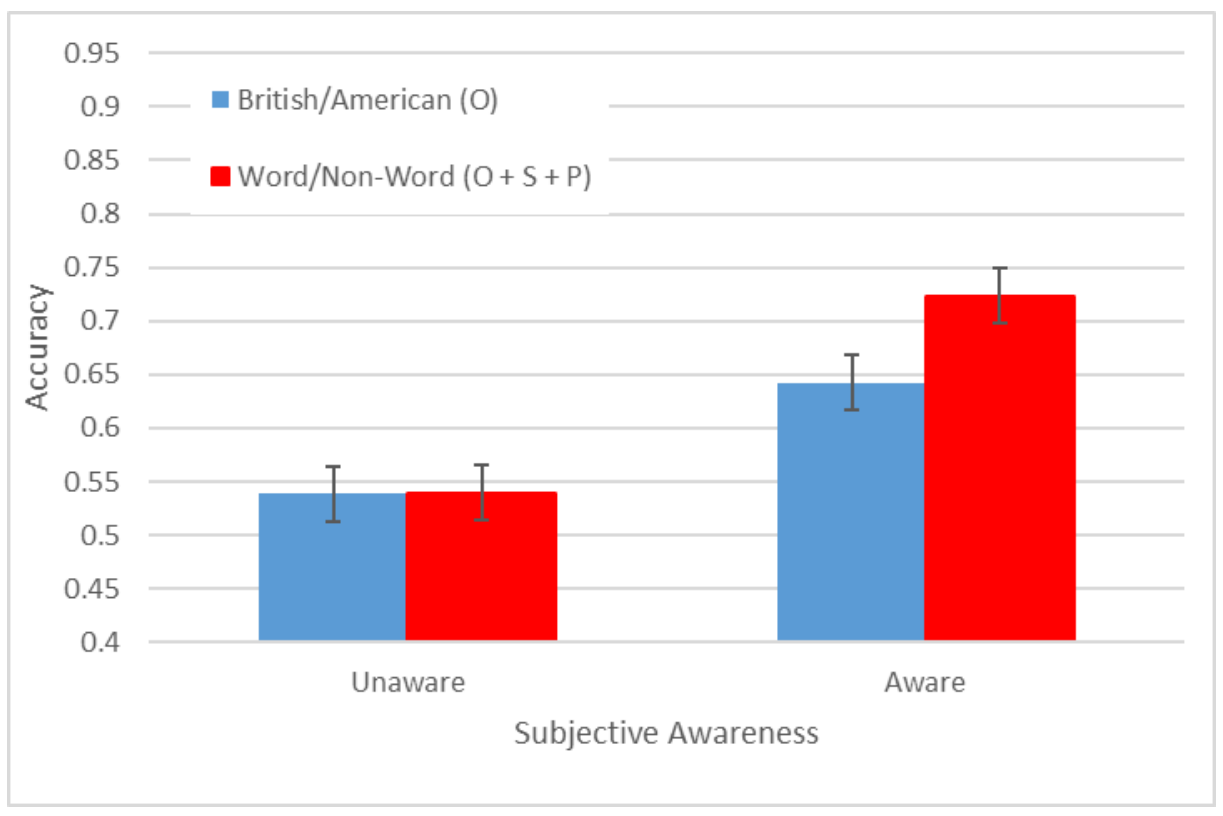

Note. The error bars represent the $95 \%$ CIs ( \pm 0.03 by-subjects and by-items). O, S, and P stand for orthographic, semantic, and phonological differences, respectively. 
Because the improved performance in the Word/Nonword condition could have been due to a participant bias towards selecting the more familiar choice (in this case, the word), we additionally examined bias and sensitivity by-subjects and by-items. This bias can be measured directly using a signal detection approach, as well as sensitivity, which is a measure of accuracy where bias has been removed. Bias was calculated using the formula for $B_{D}^{\prime \prime}$ (Stanislaw \& Todorov, 1999; see also Donaldson, 1992 \& 1996). In the British/American condition, negative $B_{D}^{\prime \prime}$ values indicate a bias towards selecting the British word (-1.0 is the maximum British bias), while positive $B_{D}^{\prime \prime}$ values indicate a bias towards selecting the American word (1.0 is the maximum American bias). In the Word/Nonword condition, negative $B_{D}^{\prime \prime}$ values indicate a bias towards selecting the Word (-1.0 is the maximum Word bias), while positive $B_{D}^{\prime \prime}$ values indicate a bias towards selecting the Nonword (1.0 is the maximum Nonword bias). One-sample t-tests indicated that in the British/American condition there was no significant bias, while in the Word/Nonword condition, participants were significantly biased towards selecting the Word (see Table 4).

\section{Table 4}

Summary of $B_{D}^{\prime \prime}$ values and one-sample t-tests

\begin{tabular}{llrrr}
\hline $\begin{array}{l}\text { By-Subjects } \\
\text { Pair Type }\end{array}$ & Awareness & $M(S E)$ & $t(22)$ & $p$ \\
\hline British/American & Unaware & $0.01(0.03)$ & 0.50 & .623 \\
& Aware & $0.06(0.06)$ & 1.08 & .291 \\
Word/Nonword & Unaware & $-0.07(0.03)$ & -2.27 & .033 \\
& Aware & $-0.40(0.09)$ & -4.49 & $<.001$ \\
\hline
\end{tabular}




\begin{tabular}{llrrr}
\hline By-Items & & & & \\
& & & & \\
& & & \\
British/American & Unaware & $0.01(0.01)$ & 1.07 & .300 \\
& Aware & $-0.04(0.07)$ & -0.62 & .542 \\
Word/Nonword & Unaware & $-0.14(0.03)$ & -4.01 & $<.001$ \\
& Aware & $-0.42(0.05)$ & -8.01 & $<.001$
\end{tabular}

Note. Negative values represent a bias towards selecting the British spelling or Word option, while positive values represent a bias towards selecting the American spelling or Nonword option.

Sensitivity was calculated using the formula for $A^{\prime}$, where 0.50 indicates chance performance (Stanislaw \& Todorov, 1999; see also Donaldson, 1992 \& 1996). According to the 2 (Pair Type: British/American vs Word/Nonword) $\times 2$ (Subjective Awareness: Unaware vs Aware) repeated measures ANOVA, there was a significant main effect of Subjective Awareness where participants' sensitivity was higher when they were not guessing $\left(M_{S}=0.73, S E_{S}=0.02\right.$; $\left.M_{I}=0.69, S E_{I}=0.03\right)$ than when they were guessing $\left(M_{S}=0.53, S E_{S}=0.01 ; M_{I}=0.55, S E_{I}=\right.$ 0.01). There was a main effect of Pair Type on sensitivity, sensitivity was higher in the Word/Nonword condition $\left(M_{S}=0.67, S E_{S}=0.01 ; M_{I}=0.66, S E_{I}=0.03\right)$ than the British/American condition $\left(M_{S}=0.60, S E_{S}=0.02 ; M_{I}=0.58, S E_{I}=0.01\right)$. The Pair Type $\times$ Subjective Awareness interaction was also significant. Table 5 summarizes these results and Figure 5 illustrates the interaction with 95\% CIs (see Loftus \& Masson, 1994), which indicate the interaction is driven by a larger effect of Pair Type when participants are not guessing. 


\section{Table 5}

Summary of Sensitivity ANOVAs

\begin{tabular}{lrrrr}
\hline By-Subjects & & & & \\
& $F(1,22)$ & $M S E$ & $p$ & $\eta_{p}{ }^{2}$ \\
\hline Subjective Awareness & 102.63 & 0.01 & $<.001$ & .82 \\
Pair Type & 17.79 & 0.01 & $<.001$ & .45 \\
Subjective Awareness x Pair Type & 12.71 & 0.01 & .002 & .37 \\
\hline By-Items & & & & \\
& $F(1,19)$ & $M S E$ & $p$ & $\eta_{p}{ }^{2}$ \\
\hline Subjective Awareness & 37.92 & 0.01 & $<.001$ & .67 \\
Pair Type & 9.67 & 0.01 & .006 & .34 \\
Subjective Awareness x Pair Type & 9.74 & 0.01 & .006 & .34 \\
\hline
\end{tabular}

\section{Figure 5}

Sensitivity as a function of Pair Type and Subjective Awareness, By-Subjects (a) and By-Items

(b)

a.

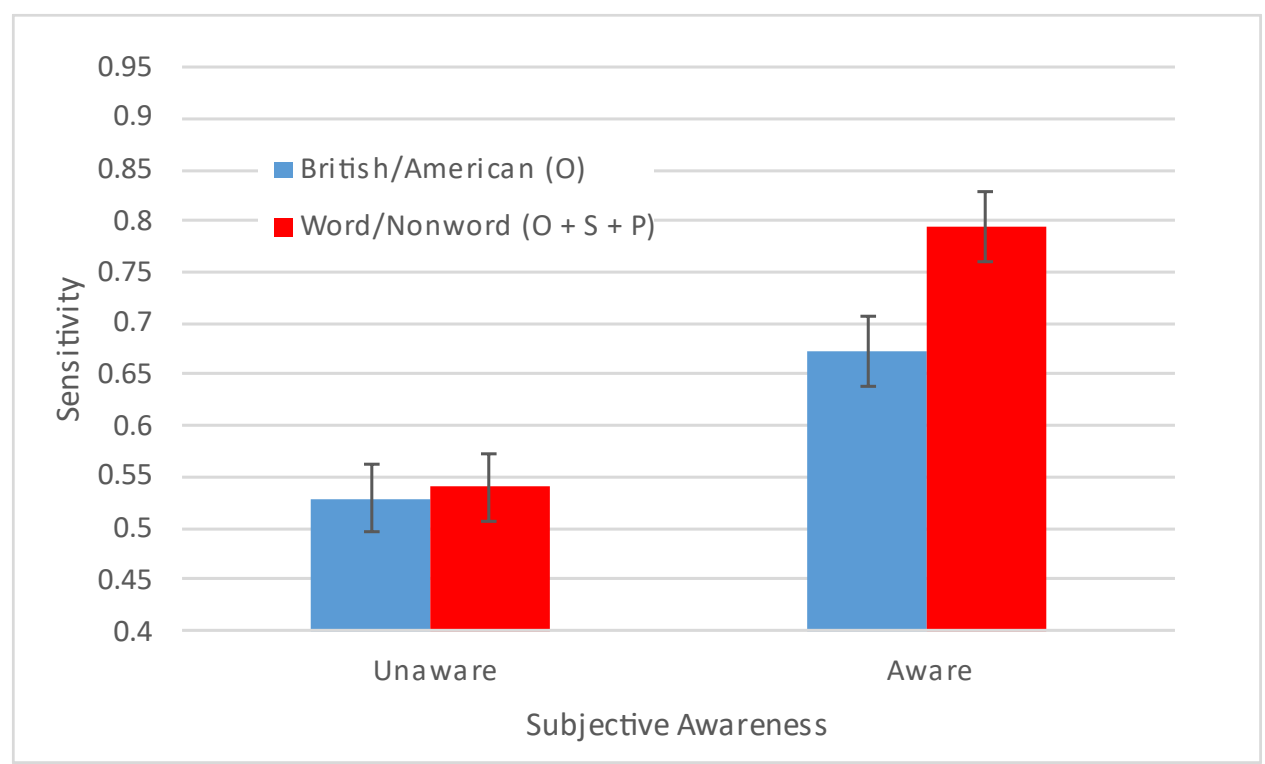


b.

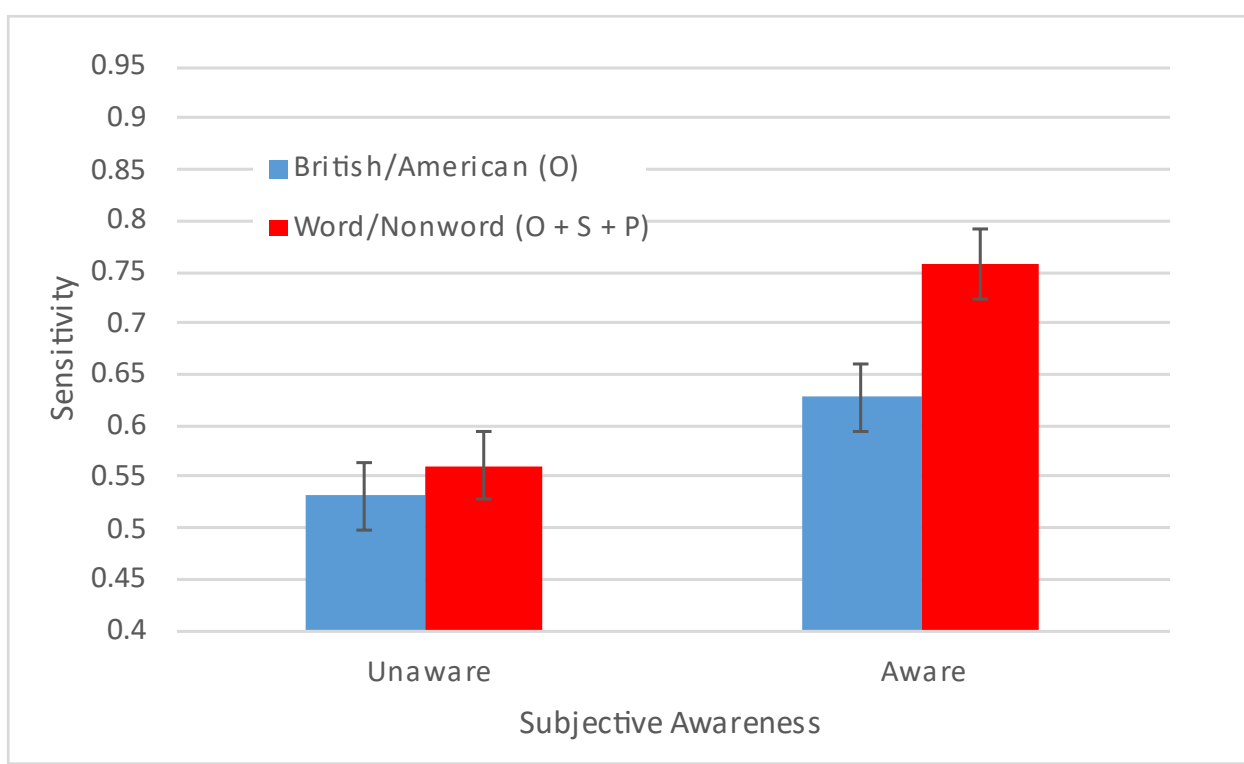

Note. The error bars represent the $95 \%$ CIs ( \pm 0.03 by-subjects and by-items). $\mathrm{O}, \mathrm{S}$, and $\mathrm{P}$ stand for orthographic, semantic, and phonological differences, respectively.

\section{Reaction Time}

A 2 (Pair Type: British/American vs Word/Nonword) × 2 (Subjective Awareness:

Unaware vs Aware) repeated measures ANOVA was conducted to analyse RT for correct trials. The median RT values were used for this analysis, as median values are less vulnerable to the effects of outliers than mean values, thus all RT values reported are the mean of medians. There was a significant main effect of subjective awareness on RT, whereby participant RTs were slower during unaware trials $\left(M_{S}=1400.69, S E_{S}=88.96 ; M_{I}=1335.30, S E_{I}=35.89\right)$, than aware trials $\left(M_{S}=1088.16, S E_{S}=44.19 ; M_{I}=1121.29, S E_{I}=35.09\right)$. There was no significant effect of pair type by-subjects or by-items, and the interaction between pair type and subjective awareness only approached significance by-subjects. These results are summarized in Table 6 and the effects are presented with 95\% CIs in Figure 6. 


\section{Table 6}

Summary of RT ANOVAs

\begin{tabular}{|c|c|c|c|c|}
\hline \multicolumn{5}{|l|}{ By-Subjects } \\
\hline & $F(1,22)$ & $M S E$ & $p$ & $\eta_{p}^{2}$ \\
\hline Subjective Awareness & 17.46 & 128663.09 & $<.001$ & .44 \\
\hline Pair Type & 0.10 & 95557.84 & .760 & .004 \\
\hline Pair Type x Subjective Awareness & 3.14 & 31819.04 & .090 & .13 \\
\hline \multicolumn{5}{|l|}{ By-Items } \\
\hline & $F(1,19)$ & $M S E$ & $p$ & $\eta_{p}^{2}$ \\
\hline Subjective Awareness & 44.63 & 20524.67 & $<.001$ & .70 \\
\hline Pair Type & 0.06 & 27365.75 & .816 & .003 \\
\hline Pair Type x Subjective Awareness & 1.14 & 27076.27 & .300 & .06 \\
\hline
\end{tabular}




\section{Figure 6}

RT as a function of Pair Type and Subjective Awareness, By-Subjects (a) and By-Items (b)

a.

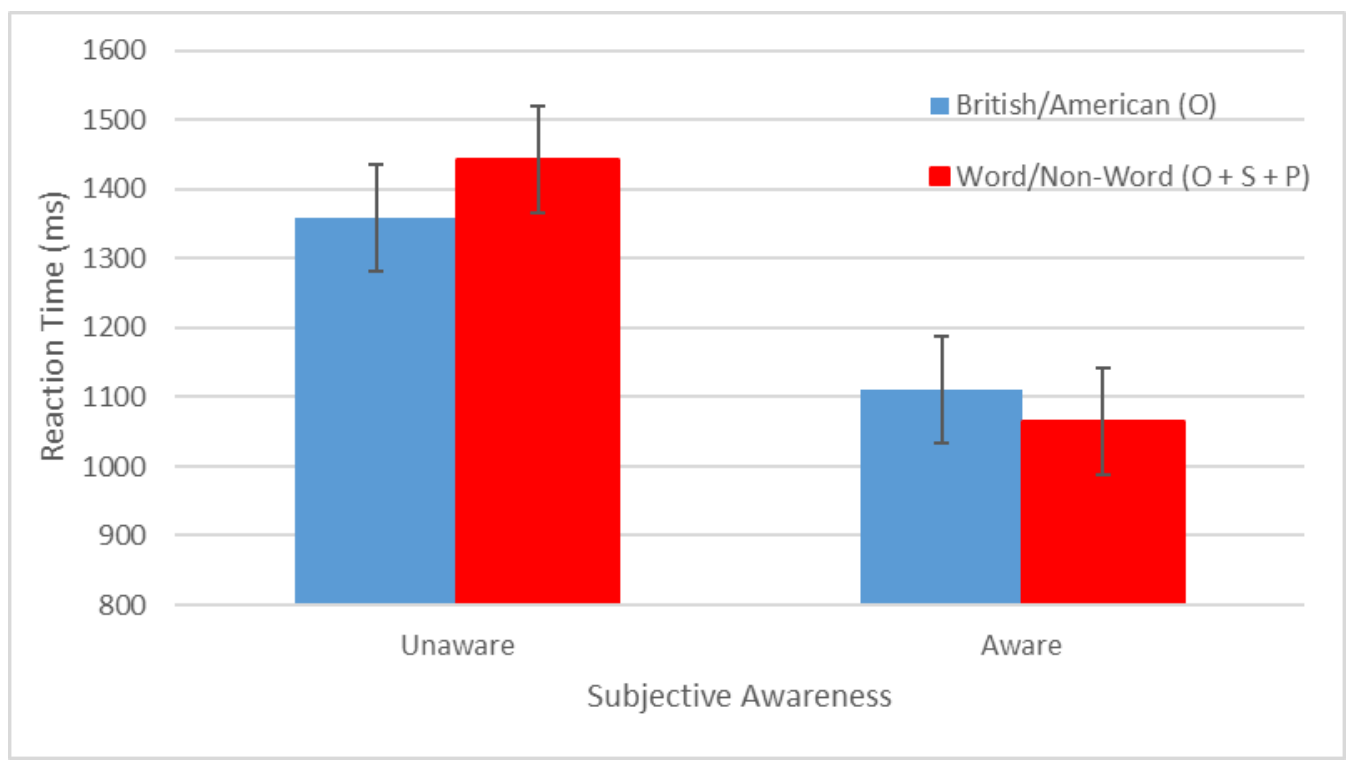

b.

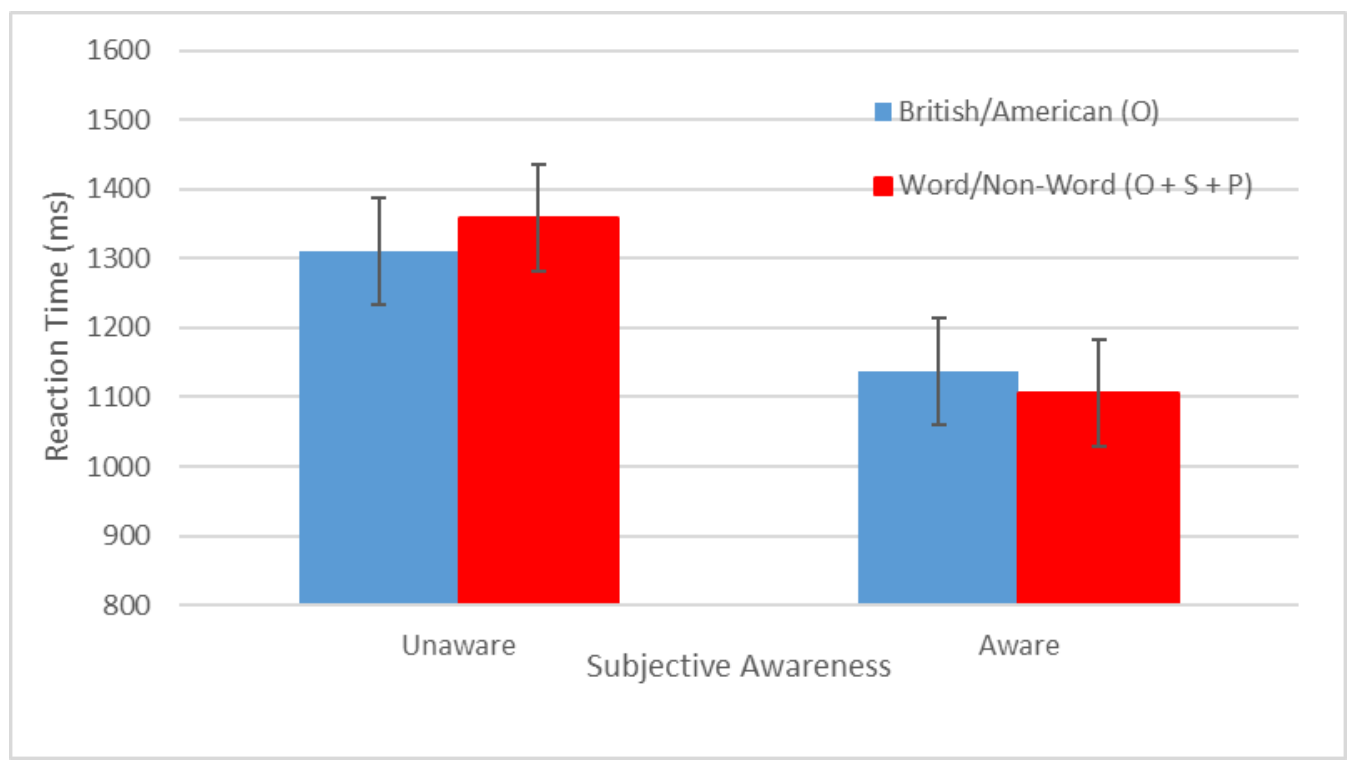

Note. The error bars represent the $95 \%$ CIs ( $\pm 77.14 \mathrm{~ms}$ by-subjects, $\pm 77.01 \mathrm{~ms}$ by-items $) . \mathrm{O}, \mathrm{S}$, and P stand for orthographic, semantic, and phonological differences, respectively. 


\section{Experiment 1 Discussion}

These results suggest that all three of orthography, semantics, and phonology are monitored in the 2AFC word/nonword task. In general, participants showed greater accuracy, sensitivity, and bias when consciously processing word/nonword pairs, which differ in orthography, phonology, and semantics, than British/American word pairs, which differ only in orthography. The interaction between pair type and subjective awareness on accuracy and sensitivity, coupled with the significant effect of pair type in the aware condition, but a lesser or no effect in the unaware condition, indicates that when participants were aware of the stimuli, they were able to utilize additional information from all three of orthography, semantics, and phonology during the word/nonword condition, boosting their accuracy and sensitivity. The agreement between accuracy and sensitivity indicates that this advantage in the word/nonword condition is due to more than a bias towards selecting the word. The aware condition also elicited significantly faster RTs than the unaware condition. These results generally support our hypotheses, and the consistency between the by-subjects/by-items ANOVAs and supplementary (G)LMM analyses (Appendix C) highlight that the effects are generalizable both to other subjects and other items. Furthermore, as can be seen by comparing the by-subjects (or by-items) Accuracy figure to the corresponding RT figure, faster RTs are generally associated with better accuracy performance, and there were no effects whereby RT and accuracy were in the same direction and both significant (i.e., significant speed-accuracy tradeoffs).

Experiment 2 was designed to replicate these results and determine whether the involvement of semantics and phonology is due to feedback to orthographic encoding.

\section{Experiment 2}


This second experiment served to replicate and extend the findings of Experiment 1 by varying the contrast between the target word and the surrounding mask as a manipulation of target visibility. This technique is typically used to manipulate orthographic encoding (e.g., Borowsky and Besner, 1993, 2006; Sternberg, 1969), and can help determine whether effects from the 2AFC word/nonword task in Experiment 1 occur at the orthographic encoding stage, as was assumed by Haro et al. (2019) who concluded in their research that semantics had a feedback influence on orthography (see also Grossi et al., 2009). When the contrast between the target and the mask is low, it would be more difficult to read the target (low visibility). When the contrast between the target and the mask is high, it would be easier to read the target (high visibility). Lower visibility should decrease orthographic encoding, lowering accuracy/sensitivity and increasing RTs. Higher visibility should increase orthographic encoding, increasing accuracy/sensitivity and reducing RTs. The manipulation of target visibility will help determine whether the systems of semantics and phonology feed back to orthographic encoding during the 2AFC task by using the additive-factors method, described next.

\section{Additive-Factors Method}

The additive-factors method (Sternberg, 1969) is useful for determining which factors influence the same or different stages of processing. Borowsky and Besner (1993) examined the effects of context, word frequency and target visibility during a lexical decision task using the additive-factors method to assess the interactions between these variables. In their study, context was defined as semantically related or unrelated primes (manipulating semantic processing), word frequency was defined as how commonly a word is encountered in print (reflecting the connections between lexical and semantic representations), and target visibility was defined by the contrast of the presented words (manipulating orthographic encoding). If two variables of 
interest are affecting different stages of processing, they will have additive effects on RT. In contrast, if the variables occur at the same stage of processing, there may be an over-additive effect on RT, whereby the influence of one variable amplifies the effects of the other variable. Borowsky and Besner (1993) discussed how target visibility can be assumed to manipulate the rate of encoding in the orthographic lexical system, so the other two variables of context and word frequency were examined to see if they also affect orthographic encoding. Borowsky \& Besner (1993) demonstrated that context interacted with target visibility, likely reflecting feedback of the semantic system to orthographic encoding in the lexical decision task. In the case of the current research, if the conclusion of Haro et al. (2019) that semantic information feeds back to orthographic encoding is correct, then additive-factors logic would predict that overadditive effects between pair type and target visibility on RT should be observed.

\section{Summary and Hypotheses}

Experiment 2 is an extension of Experiment 1, using the additive-factors method by manipulating orthographic encoding through target visibility to determine whether visibility interacts with the pair type conditions, as would be predicted if semantic/phonological processing results in feedback to orthographic encoding in the 2AFC task. To manipulate visibility, Experiment 2 included both low visibility trials (where the target and mask are the same brightness, these were the trials present in Experiment 1) and high visibility trials (where the target is brighter than the mask, these trials were new to Experiment 2). There are three hypotheses of interest in Experiment 2:

1. As in Experiment 1, participants should be better at discriminating between word/nonword pairs than British/American pairs.

2. As in Experiment 1, participants should be faster and more accurate/sensitive in the 
aware condition (i.e., above the subjective threshold of awareness), and the effects of pair type on accuracy/sensitivity should also be strongest.

3. Target visibility should affect orthographic encoding such that if the target word is brighter than the mask, then performance in terms of accuracy, sensitivity, and RT should be better than when the target is the same brightness as the mask. Given that Target Visibility manipulates orthographic encoding, if semantic/phonological feedback to orthographic encoding is occurring then the effect of pair type should interact with target visibility in an overadditive fashion on RT. If such feedback is not occurring, then these factors should not produce an overadditive interaction. See Figure 7 for illustrations of distributed memory model variants that would explain the results. Note how in Figure 7a, only orthography is involved in the $2 \mathrm{AFC}$ output, but phonology and semantics contribute through feedback mechanisms. Contrast this to Figure 7b, where all three of orthography, phonology and semantics are involved through familiarity-activation monitoring of the whole network, and no feedback mechanisms are present. 


\section{Figure 7}

Models of language representation and expected results iffeedback is present (a) or feedback is absent (b).

a.

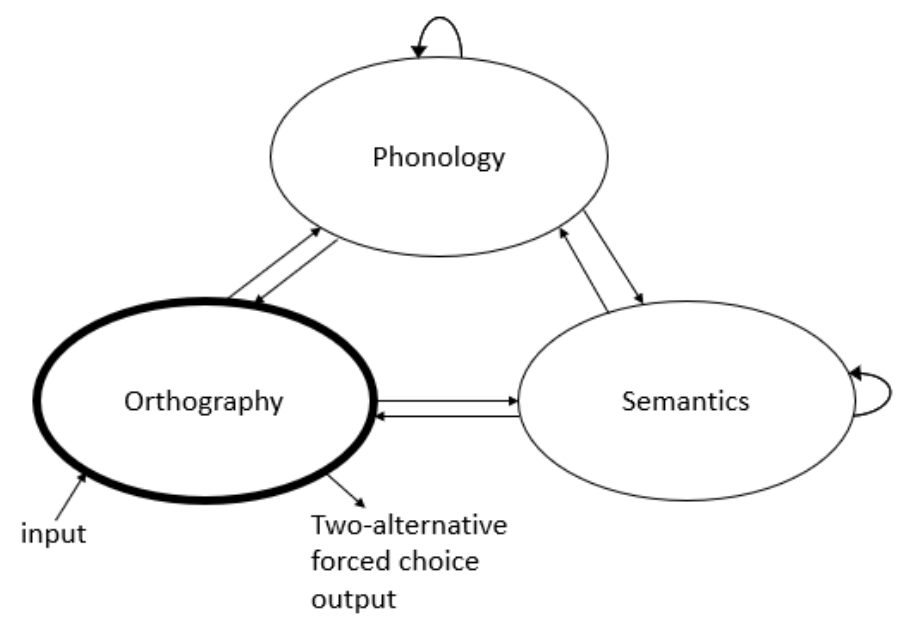

b.

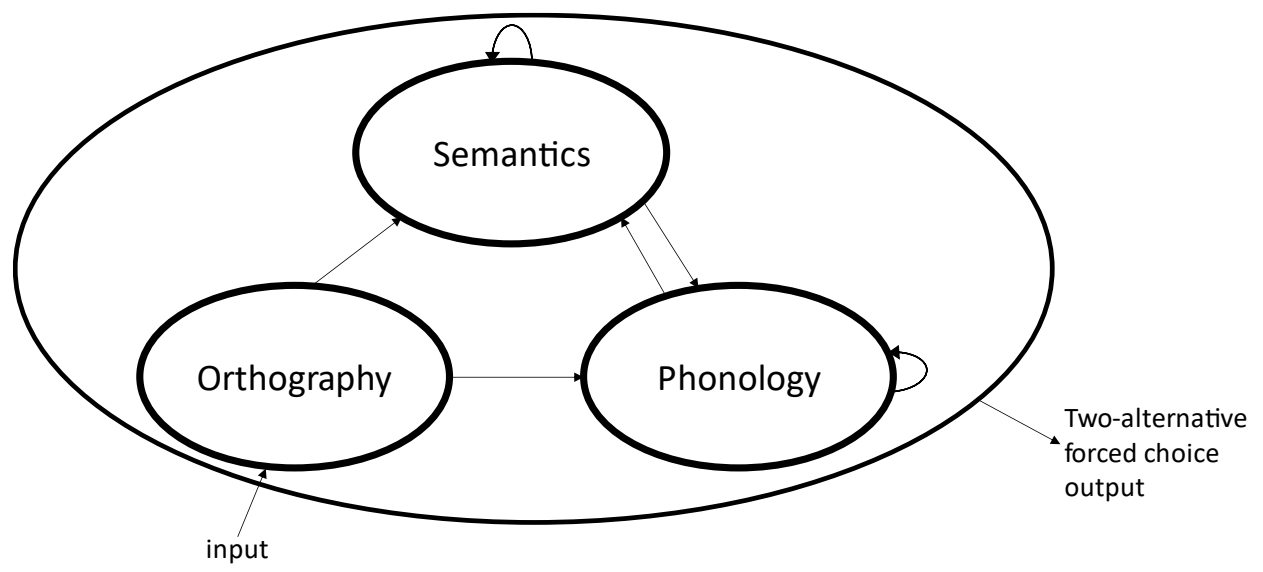




\section{Methods}

\section{Participants}

To have the same statistical power as in Experiment 1, 24 participants $(M=21.17$ years, $S E=0.61$ years, 18 to 33 years; 19 female, 5 male) were recruited through the University of Saskatchewan Participant Pool, and received bonus course credit in exchange for their participation. The first language of all participants was English.

\section{Apparatus and Stimuli}

The apparatus used in Experiment 2 was identical to that of Experiment 1. The British/American and word/nonword pairs were identical to Experiment 1 . Only $40 \mathrm{~ms}$ and 53 ms durations were used in this experiment, based on the results of Experiment 1 that suggested the $27 \mathrm{~ms}$ duration was too difficult for participants. In the high contrast condition, the mask was set to an RGB value of 20, 20, 20, while the text was white (an RGB value of 255, 255, 255). During the low contrast condition, both mask and text were white (replicating Experiment 1). Both durations had trials at each contrast level, leading to four contrast-duration combinations (Low Contrast-40 ms, High Contrast-40 ms, Low Contrast-53 ms, High Contrast-53 ms). In the British/American block, there were 40 trials per contrast-duration combination, for a total of 160 trials. The word/nonword block also had 40 trials per contrast-duration combination, for a total of 160 trials. The word selection in the word/nonword block used the same counterbalancing technique as Experiment 1. The order of the British/American trial block and word/nonword trial block was counterbalanced in the same manner as Experiment 1 . The high contrast and low contrast trials for each pair type occurred in the same block and order of trials within the blocks was randomized. 


\section{Figure 8}

Experiment 2 Trial Progression
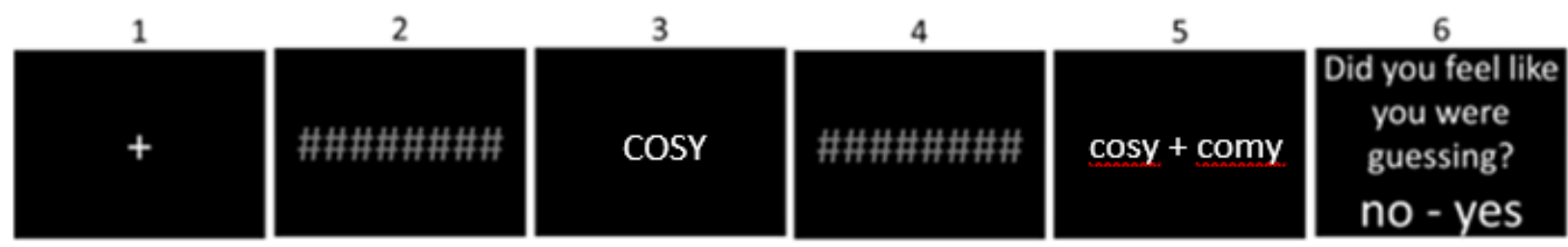

Note. High contrast trial progression from: (1) fixation cross, (2) to pre-mask for $53 \mathrm{~ms}$, to (3) target for either $40 \mathrm{~ms}$ or $53 \mathrm{~ms}$, to (4) post-mask for $53 \mathrm{~ms}$, to (5) $50 \mathrm{~ms}$ blank screen followed by the 2AFC probes, to (6) subjective threshold assessment.

\section{Procedure}

The procedure was nearly identical to that of the first experiment, with the following exception: Participants encountered both low contrast trials (see Figure 3; these trials replicate Experiment 1), and high contrast trials (see Figure 8).

\section{Results}

As in Experiment 1, we evaluated accuracy with one-sample t-tests to determine when participants were performing at above chance accuracy. These t-tests are summarized in Table 7, by-subjects and by-items. Table 8 reports the proportion of Aware trials for the different conditions in Experiment 2. 


\section{Table 7}

Accuracy as a function of Pair Type, Target Visibility, and Subjective Awareness Level

\section{By-Subjects}

\begin{tabular}{|c|c|c|c|c|c|}
\hline \multicolumn{4}{|l|}{ Low Contrast } & \multicolumn{2}{|c|}{ Difference from Chance } \\
\hline & \multicolumn{3}{|l|}{ Subjective } & & \\
\hline Pair Type & Awareness & $M$ & $S E$ & $t(23)$ & $p$ \\
\hline \multirow[t]{2}{*}{ British/ American } & Unaware & 0.55 & 0.02 & 3.18 & .004 \\
\hline & Aware & 0.77 & 0.03 & 7.77 & $<.001$ \\
\hline \multirow[t]{2}{*}{ Word/ Nonword } & Unaware & 0.60 & 0.02 & 4.83 & $<.001$ \\
\hline & Aware & 0.79 & 0.03 & 9.12 & $<.001$ \\
\hline \multicolumn{4}{|l|}{ High Contrast } & \multicolumn{2}{|c|}{ Difference from Chance } \\
\hline & \multicolumn{3}{|l|}{ Subjective } & & \\
\hline Pair Type & Awareness & $M$ & $S E$ & $t(23)$ & $p$ \\
\hline \multirow[t]{2}{*}{ British/ American } & Unaware & 0.57 & 0.04 & 1.98 & .060 \\
\hline & Aware & 0.82 & 0.03 & 11.95 & $<.001$ \\
\hline \multirow[t]{2}{*}{ Word/ Nonword } & Unaware & 0.58 & 0.03 & 2.55 & .018 \\
\hline & Aware & 0.89 & 0.02 & 24.22 & $<.001$ \\
\hline
\end{tabular}

\section{By-Items}

Low Contrast

Subjective

Pair Typ

British/ American

Awareness

Unaware

$M$

$S E$

$t(19)$

$p$

.56

.02

3.40

.003

Aware

.67

.03

4.94

$<.001$ 


\begin{tabular}{|c|c|c|c|c|c|}
\hline \multirow[t]{2}{*}{ Word/ Nonword } & Unaware & .62 & .03 & 4.22 & $<.001$ \\
\hline & Aware & .79 & .03 & 10.13 & $<.001$ \\
\hline \multicolumn{4}{|l|}{ High Contrast } & \multicolumn{2}{|c|}{ Difference from Chance } \\
\hline & \multicolumn{5}{|l|}{ Subjective } \\
\hline Pair Type & Awareness & $M$ & $S E$ & $t(19)$ & $p$ \\
\hline \multirow[t]{2}{*}{ British/ American } & Unaware & .62 & .02 & 6.51 & $<.001$ \\
\hline & Aware & .76 & .03 & 8.19 & $<.001$ \\
\hline \multirow[t]{2}{*}{ Word/ Nonword } & Unaware & .64 & .02 & 5.22 & $<.001$ \\
\hline & Aware & .87 & .03 & 11.41 & $<.001$ \\
\hline
\end{tabular}




\section{Table 8}

Proportion of Aware responses for the different Experiment 2 conditions

\section{Proportion}

Condition

All Trials (Correct Trials Only)

\begin{tabular}{llc} 
British/American & Low Contrast & $0.32(0.38)$ \\
\cline { 2 - 3 } & High Contrast & $0.73(0.78)$ \\
\hline Word/Nonword & Low Contrast & $0.38(0.45)$ \\
\cline { 2 - 3 } & High Contrast & $0.82(0.87)$ \\
\hline
\end{tabular}

\section{Accuracy}

A 2 (Pair Type: British/American vs Word/Nonword) $\times 2$ (Subjective Awareness: Unaware vs Aware $) \times 2$ (Target Visibility: High Contrast vs Low Contrast) repeated measures ANOVA was used to analyze accuracy. There was a main effect of subjective awareness on accuracy; participants were more accurate during aware trials $\left(M_{S}=0.81, S E_{S}=0.02 ; M_{I}=0.77\right.$, $\left.S E_{I}=0.03\right)$ than unaware trials $\left(M_{S}=0.57, S E_{S}=0.02 ; M_{I}=0.61, S E_{I}=0.01\right.$. There was also a main effect of pair type. Participants were more accurate when they encountered word/nonword pairs $\left(M_{S}=0.71, S E_{S}=0.02 ; M_{I}=0.73, S E_{I}=0.02\right)$ than British/American pairs $\left(M_{S}=0.67, S E_{S}\right.$ $\left.=0.02 ; M_{I}=0.65, S E_{I}=0.02\right)$. A main effect of target visibility was significant as well in both ANOVAs. Participants were more accurate when stimulus contrast (our target visibility manipulation) was high $\left(M_{S}=0.71, S E_{S}=0.02 ; M_{I}=0.72, S E_{I}=0.02\right)$ than low $\left(M_{S}=0.67, S E_{S}\right.$ $\left.=0.02 ; M_{I}=0.66, S E_{I}=0.02\right)$. The Pair Type $\times$ Subjective Awareness interaction was not significant by-subjects, but was significant by-items. There was also a Target Visibility $\times$ 
Subjective Awareness interaction by-subjects, which approached significance by-items. The other interactions were not significant, and the results are summarized in Table 9.

\section{Table 9}

Summary of Accuracy ANOVAs

\section{By- Subjects}

\begin{tabular}{|c|c|c|c|c|}
\hline & $F(1,23)$ & $M S E$ & $p$ & $\eta_{p}^{2}$ \\
\hline Subjective Awareness & 170.64 & 0.02 & $<.001$ & .88 \\
\hline Pair Type & 5.30 & 0.02 & .031 & .19 \\
\hline Target Visibility & 10.34 & 0.007 & .004 & .31 \\
\hline Pair Type x Subjective Awareness & 1.27 & 0.007 & .272 & .05 \\
\hline Subjective Awareness x Target Visibility & 9.70 & 0.01 & .005 & .30 \\
\hline Pair Type x Target Visibility & 0.04 & 0.009 & .841 & .002 \\
\hline
\end{tabular}

Subjective Awareness x Pair Type x Target

Visibility

$1.84 \quad 0.01$

.189

.07

\section{By- Items}

\begin{tabular}{lrrrr} 
& $F(1,19)$ & $M S E$ & $p$ & $\eta_{p}^{2}$ \\
& & & & .79 \\
\hline Subjective Awareness & 69.93 & 0.02 & $<.001$ & .57 \\
Pair Type & 24.90 & 0.01 & $<.001$ & .32 \\
Target Visibility & 8.75 & 0.02 & .008 & .51 \\
Pair Type x Subjective Awareness & 19.37 & 0.004 & $<.001$ & .15 \\
Subjective Awareness x Target Visibility & 3.44 & 0.006 & .088 & .03 \\
Pair Type x Target Visibility & & & & \\
\end{tabular}


Subjective Awareness x Pair Type x Target

Visibility

$\begin{array}{lll}0.34 & 0.005 \quad .565\end{array}$

.02 
95\% CIs were used to assess the Target Visibility $\times$ Subjective Awareness interaction, similar to Experiment 1. Based on the $95 \%$ CIs, when participants were not guessing, participants were more accurate during high contrast trials than low contrast trials (see Figure 9). The difference in the effect of target visibility for the unaware compared to the aware condition accounts for the Target Visibility $\times$ Subjective Awareness interaction found in the initial ANOVA. Further, during the aware high contrast condition, participants were more accurate for the word/nonword pairs than the British/American pairs, but this was not the case during the low contrast condition, as indicated by the $95 \%$ CIs. When participants were unaware of the stimuli there were no significant differences in participant accuracy (with the exception of the word/nonword low contrast condition being significantly more accurate than the British/American low contrast condition by-subjects), even though many of these conditions were significantly above chance accuracy. This accounts for the Pair Type $\times$ Subjective Awareness interaction that was found in the repeated measures ANOVA.

Because the Pair Type $\times$ Target Visibility interaction test is critical to our third hypothesis (although the additive factors method focuses on RT, which is presented below, we examined this on accuracy as well), a Bayesian analysis (see Rouder et al., 2009) was used to further assess this additive effect. The JZS Bayes Factor by-subjects was calculated to be 6.25 (4.29 by-items), and with priors assumed to be one, we calculated the posterior probability of .86 (.81 by-items), indicating positive evidence in favour of the null hypothesis (see Masson, 2011). 


\section{Figure 9}

Accuracy as a function of Pair Type, Target Visibility, and Subjective Awareness, By-Subjects (a) and By-Items (b)

a.

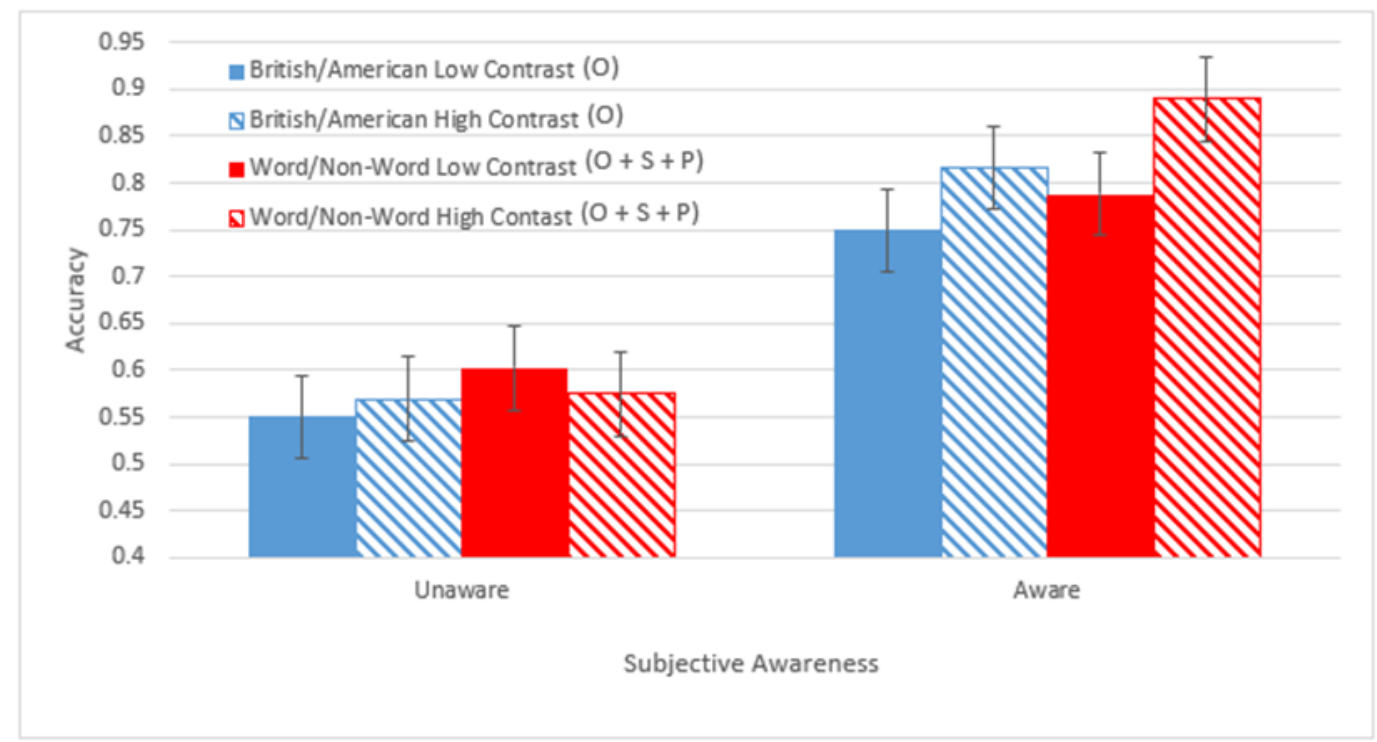

b.

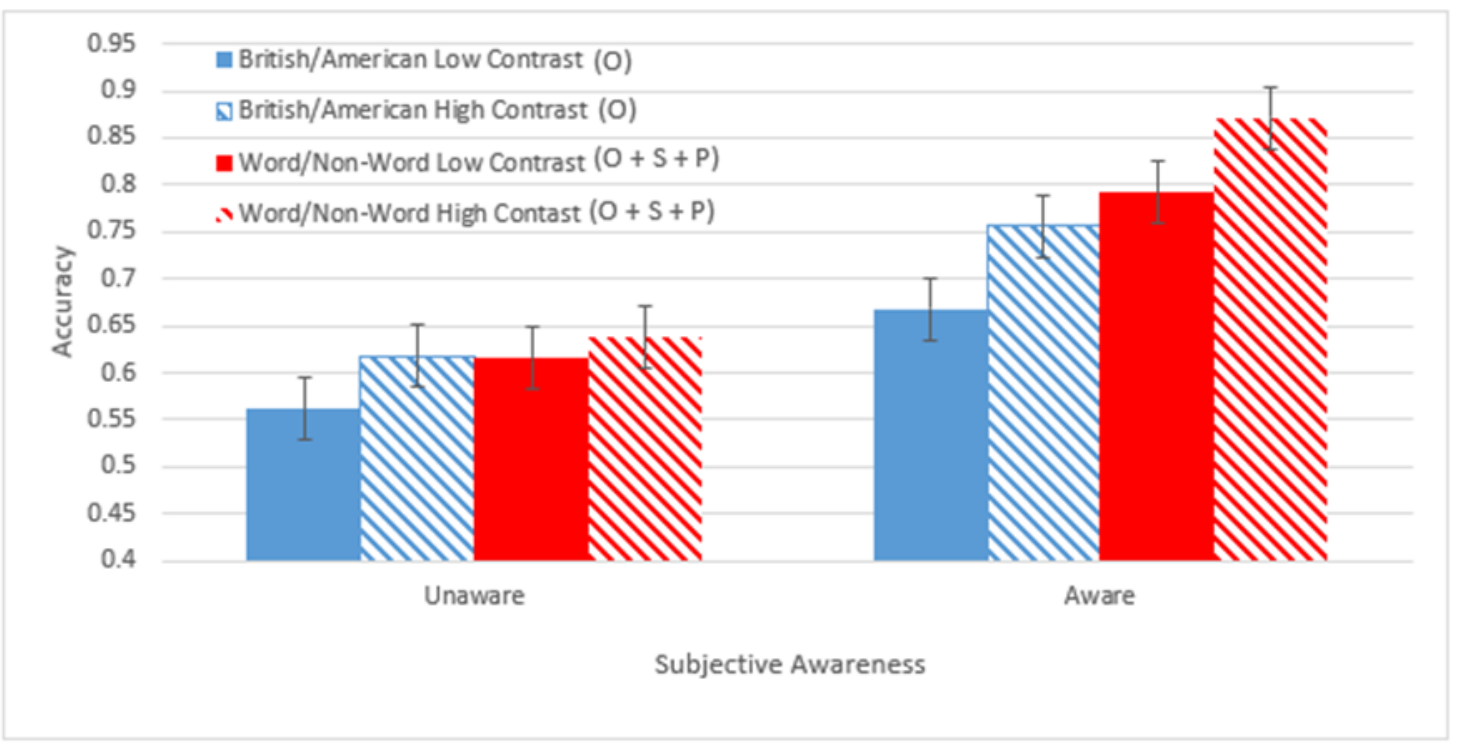

Note. The error bars represent $95 \%$ CIs (by-subjects \pm 0.04 ; by-items \pm 0.03 ). $\mathrm{O}, \mathrm{S}$, and $\mathrm{P}$ stand for orthographic, semantic, and phonological differences, respectively. 
As in Experiment 1, we additionally examined bias and sensitivity by-subjects and byitems. Three participants were excluded from the by-subjects analysis for never guessing in the high contrast condition for some target conditions. One item was excluded from the by-items analysis because participants never guessed when this item was presented in one target condition. One-sample t-tests indicated that in the British/American condition there was no significant bias, while in the Word/Nonword condition, participants were significantly biased towards selecting the Word (see Table 10).

\section{Table 10}

Summary of $B_{D}^{\prime \prime}$ values and one-sample t-tests

\begin{tabular}{|c|c|c|c|c|c|}
\hline \multicolumn{6}{|l|}{ By-Subjects } \\
\hline \multirow[b]{2}{*}{ Pair Type } & \multicolumn{5}{|l|}{ Target } \\
\hline & Visibility & Awareness & $M(S E)$ & $t(20)$ & $p$ \\
\hline \multirow[t]{4}{*}{ British/American } & Low Contrast & Unaware & $-0.03(0.02)$ & -1.49 & .152 \\
\hline & & Aware & $-0.06(0.09)$ & -0.63 & .533 \\
\hline & High Contrast & Unaware & $0.16(0.10)$ & 1.65 & .114 \\
\hline & & Aware & $0.05(0.06)$ & 0.76 & .459 \\
\hline \multirow[t]{4}{*}{ Word/Nonword } & Low Contrast & Unaware & $-0.17(0.04)$ & -3.91 & $<.001$ \\
\hline & & Aware & $-0.31(0.09)$ & -3.54 & .002 \\
\hline & High Contrast & Unaware & $-0.26(0.15)$ & -1.76 & .094 \\
\hline & & Aware & $-0.65(0.08)$ & -7.92 & $<.001$ \\
\hline \multicolumn{6}{|l|}{ By-Items } \\
\hline & & & $M(S E)$ & $t(18)$ & $p$ \\
\hline \multirow[t]{4}{*}{ British/American } & Low Contrast & Unaware & $-0.003(0.01)$ & -0.25 & .806 \\
\hline & & Aware & $0.07(0.08)$ & 0.83 & .417 \\
\hline & High Contrast & Unaware & $0.05(0.10)$ & 0.47 & .641 \\
\hline & & Aware & $0.01(0.10)$ & 0.13 & .897 \\
\hline
\end{tabular}




\begin{tabular}{lrrrrr}
\hline Word/Nonword & Low Contrast & Unaware & $-0.08(0.03)$ & -3.17 & .005 \\
& & Aware & $-0.25(0.08)$ & -3.34 & .004 \\
& High Contrast & Unaware & $-0.38(0.09)$ & -4.07 & $<.001$ \\
& & Aware & $-0.51(0.09)$ & -5.42 & $<.001$ \\
\hline
\end{tabular}

Note. Negative values represent a bias towards selecting the British spelling or Word option, while positive values represent a bias towards selecting the American spelling or Nonword option.

According to the 2 (Pair Type: British/American vs Word/Nonword) $\times 2$ (Subjective Awareness: Unaware vs Aware) $\times 2$ (Target Visibility: Low Contrast vs High Contrast) repeated measures ANOVA on sensitivity, there was a significant main effect of Awareness, sensitivity was better when participants stated they were aware of the target $\left(M_{\mathrm{S}}=0.82, S E_{S}=0.03 ; M_{\mathrm{I}}=\right.$ $\left.0.76, S E_{I}=0.03\right)$ compared to when they said they were guessing $\left(M_{\mathrm{S}}=0.60, S E_{S}=0.02 ; M_{\mathrm{I}}=\right.$ $\left.0.60, S E_{I}=0.02\right)$. There was also a significant main effect of Pair Type, sensitivity was higher during the Word/Nonword condition $\left(M_{\mathrm{S}}=0.75, S E_{S}=0.02 ; M_{\mathrm{I}}=0.72, S E_{I}=0.02\right)$ than the British/American condition $\left(M_{\mathrm{S}}=0.67, S E_{S}=0.03 ; M_{\mathrm{I}}=0.65, S E_{I}=0.02\right)$. Finally, the main effect of Target Visibility was significant, sensitivity was higher during the High Contrast condition $\left(M_{\mathrm{S}}=0.74, S E_{S}=0.02 ; M_{\mathrm{I}}=0.73, S E_{I}=0.02\right)$ than the Low Contrast condition $\left(M_{\mathrm{S}}=\right.$ $\left.0.68, S E_{S}=0.03 ; M_{\mathrm{I}}=0.64, S E_{I}=0.02\right)$. The Subjective Awareness $\times$ Pair Type and Subjective Awareness $\times$ Target Visibility interactions were significant by-items but not by-subjects. The other interactions were not significant by-subjects or by-items. Table 11 summarizes these results and Figure 10 illustrates the results with $95 \%$ CIs.

Because the Pair Type $\times$ Target Visibility interaction test is critical to our third hypothesis (although the additive factors method focuses on RT, which is presented below), a Bayesian analysis (see Rouder et al., 2009) was used to further assess this additive effect. The JZS Bayes Factor by-subjects was calculated to be 4.52 (3.60 by-items), and with priors assumed 
to be one, we calculated the posterior probability of 0.81 (.78 by-items), indicating positive evidence in favour of the null hypothesis (see Masson, 2011). 


\section{Table 11}

Summary of Sensitivity ANOVAs

\begin{tabular}{lrrrr}
\hline By-Subjects & & & & \\
& $F(1,20)$ & $M S E$ & $p$ & $\eta_{p}{ }^{2}$ \\
\hline Subjective Awareness & 84.02 & 0.02 & $<.001$ & .81 \\
Pair Type & 12.55 & 0.02 & .002 & .39 \\
Target Visibility & 13.27 & 0.01 & .002 & .40 \\
Subjective Awareness $\times$ Pair Type & 0.05 & 0.01 & .829 & .002 \\
Subjective Awareness $\times$ Target Visi- & & & & \\
bility & 3.03 & 0.01 & .097 & .13 \\
Pair Type $\times$ Target Visibility & 0.72 & 0.01 & .407 & .04 \\
Subjective Awareness $\times$ Pair Type $\times$ & & & & \\
Target Visibility & 2.16 & 0.01 & .157 & .10 \\
\hline By-Items & & & & \\
& $F(1,18)$ & $M S E$ & $p$ & $\eta_{p}{ }^{2}$ \\
\hline Subjective Awareness & 59.21 & 0.02 & $<.001$ & .77 \\
Pair Type & 10.12 & 0.02 & .005 & .36 \\
Target Visibility & 27.20 & 0.01 & $<.001$ & .60 \\
Subjective Awareness x Pair Type & 10.75 & 0.01 & .004 & .37 \\
Subjective Awareness $\times$ Target Visi- & & & & .001 \\
bility & 14.02 & 0.01 & .001 & .44 \\
Pair Type $\times$ Target Visibility & 0.99 & 0.01 & .334 & .05 \\
Subjective Awareness $\times$ Pair Type $\times$ & & & & \\
Target Visibility & 2.78 & 0.01 & .113 & .13 \\
\hline
\end{tabular}




\section{Figure 10}

Sensitivity as a function of Pair Type and Subjective Awareness, By-Subjects (a) and By-Items

(b)

a.

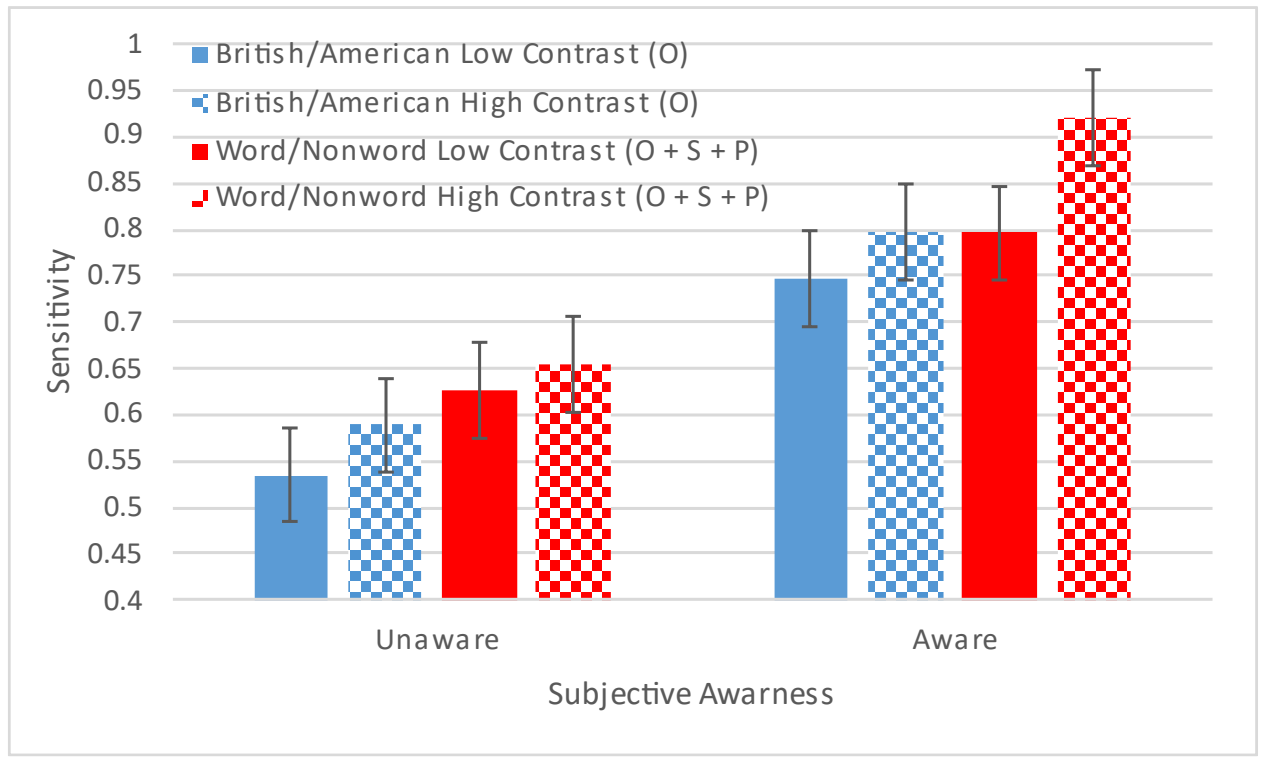

b.

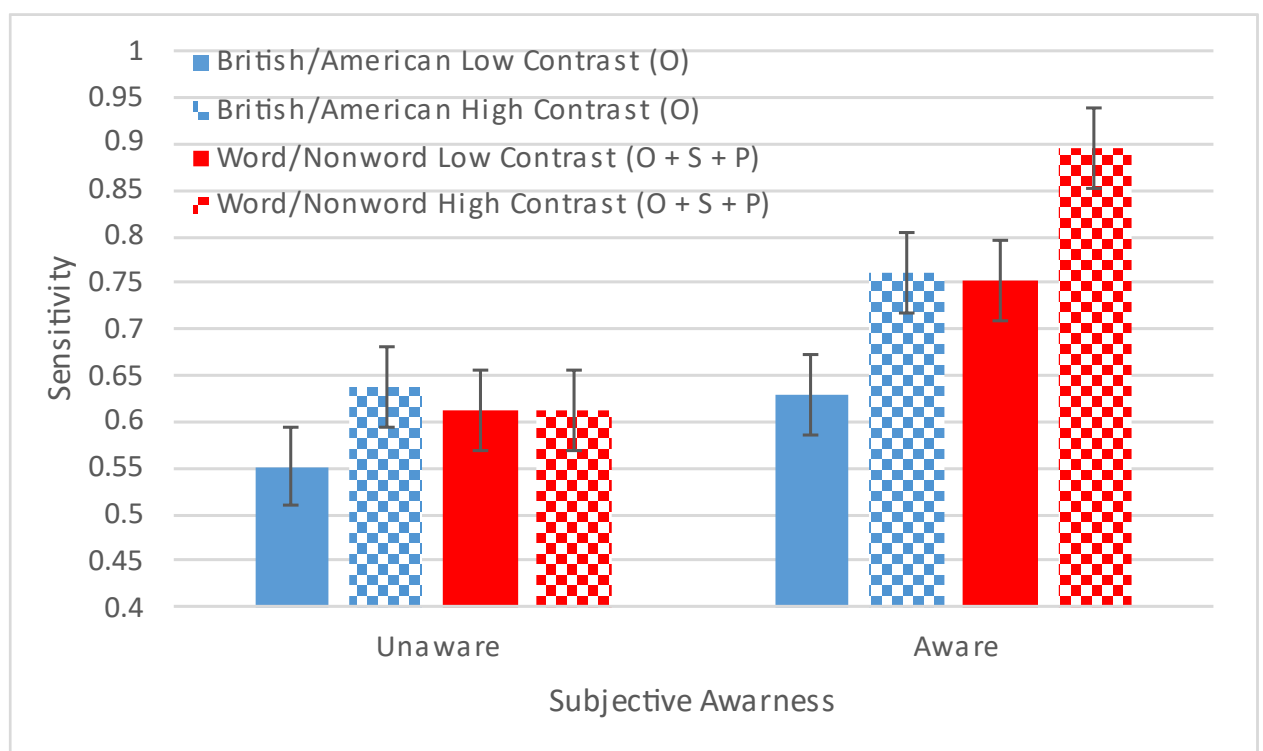

Note. The error bars represent the $95 \%$ CIs ( \pm 0.05 by-subjects, \pm 0.04 by-items). $\mathrm{O}, \mathrm{S}$, and

P stand for orthographic, semantic, and phonological differences, respectively. 


\section{Reaction Time}

A 2 (Pair Type: British/American vs Word/Nonword) $\times 2$ (Subjective Awareness: Unaware vs Aware) $\times 2$ (Target Visibility: High Contrast vs Low Contrast) repeated measures ANOVA was used to analyze RT for correct trials. As in Experiment 1, all RT values reported are the mean of medians. The only significant main effect on RT was subjective awareness, participants were slower when they were unaware of the stimuli $\left(M_{S}=1355.72 \mathrm{~ms}, S E_{S}=87.05\right.$; $\left.M_{I}=1267.98 \mathrm{~ms}, S E_{I}=32.97\right)$ than when they were aware of the stimuli $\left(M_{S}=937.32, S E_{S}=\right.$ 43.32; $\left.M_{I}=913.50 \mathrm{~ms}, S E_{I}=22.45\right)$. The other main effects and interactions were not significant. Table 12 and Figure 11 summarize these results. As in the accuracy analysis, Bayesian statistics were used to examine the Pair Type $\times$ Target Visibility interaction. The JZS Bayes Factor was calculated to be 3.85 by-subjects ( 5.46 by-items), and with priors assumed to be one, we calculated the posterior probability of .79 (0.85 by-items), indicating positive evidence in favour of the null hypothesis 5 .

\footnotetext{
${ }^{5} \mathrm{We}$ conducted an additional analysis to examine only subjects or items which had both an effect of Contrast (High Contrast condition faster than Low Contrast condition) and an effect of Pair Type (Word/Nonword condition faster than British/American condition). The intention of this analysis is to test whether an interaction emerges if only items which exhibited the effects of Contrast and Pair Type are considered (see Borowsky \& Besner, 1993, for a similar analysis). Only Aware trials were included in this analysis. 10 out of 24 subjects and 8 out of 20 items exhibited both a main effect of Contrast and a main effect of Pair Type for RT. The 2 (Contrast: Low vs High) $\times 2$ (Pair Type: British/American vs Word/Nonword) indicated there was a main effect of Pair Type, $F_{S}(1,9)=12.02, p$ $=.007, \eta_{p}^{2}=.57, F_{I}(1,7)=9.99, p=.016, \eta_{p}^{2}=.59$, and a main effect of Contrast, $F_{S}(1,9)=10.64, p=.010, \eta_{p}^{2}=$ $.54, F_{I}(1,7)=10.04, p=.016, \eta_{p}{ }^{2}=.59$. The Pair Type $\times$ Contrast interaction was not significant, $F_{S}(1,9)=.17, p=$ $.691, \eta_{p}^{2}=.02, F_{I}(1,7)=0.34, p=.577, \eta_{p}{ }^{2}=.05$. The JZS Bayes Factor was calculated to be 3.97 by-subjects $(3.34$ by-items), and with priors assumed to be one, we calculated the posterior probability of .80 ( 0.77 by-items), indicating positive evidence in favour of the null hypothesis. An LMM on this subset of data was also conducted, see Appendix C.
} 


\section{Table 12}

Summary of RT ANOVAs

\section{By- Subjects}

\begin{tabular}{|c|c|c|c|c|}
\hline & $F(1,23)$ & $M S E$ & $p$ & $\eta_{p}{ }^{2}$ \\
\hline Subjective Awareness & 58.56 & 143482.83 & .001 & .72 \\
\hline Pair Type & 1.40 & 125837.44 & .250 & .06 \\
\hline Target Visibility & 0.000 & 61395.77 & .999 & .000 \\
\hline Pair Type x Subjective Awareness & 0.52 & 40601.79 & .480 & .02 \\
\hline Subjective Awareness x Target Visibility & 2.78 & 81167.63 & .109 & .11 \\
\hline Pair Type x Target Visibility & 1.06 & 25912.52 & .313 & .04 \\
\hline \multicolumn{5}{|l|}{ Subjective Awareness x Pair Type x Target } \\
\hline Visibility & 0.49 & 30940.23 & .490 & .02 \\
\hline \multicolumn{5}{|l|}{ By-Items } \\
\hline & $F(1,19)$ & $M S E$ & $p$ & $\eta_{p}{ }^{2}$ \\
\hline Subjective Awareness & 167.30 & 30041.72 & $<.001$ & .90 \\
\hline Pair Type & 0.21 & 39447.65 & .649 & .01 \\
\hline Target Visibility & 0.001 & 33067.91 & .973 & .000 \\
\hline Pair Type x Subjective Awareness & 1.02 & 13378.45 & .325 & .05 \\
\hline Subjective Awareness x Target Visibility & 1.28 & 21988.00 & .273 & .06 \\
\hline Pair Type x Target Visibility & 0.15 & 17284.95 & .705 & .008 \\
\hline \multicolumn{5}{|l|}{ Subjective Awareness x Pair Type x Target } \\
\hline Visibility & 0.02 & 23879.08 & .895 & .001 \\
\hline
\end{tabular}




\section{Figure 11}

RT as a function of Pair Type, Target Visibility, and Subjective Awareness, By-Subjects (a) and By-Items (b)

a.

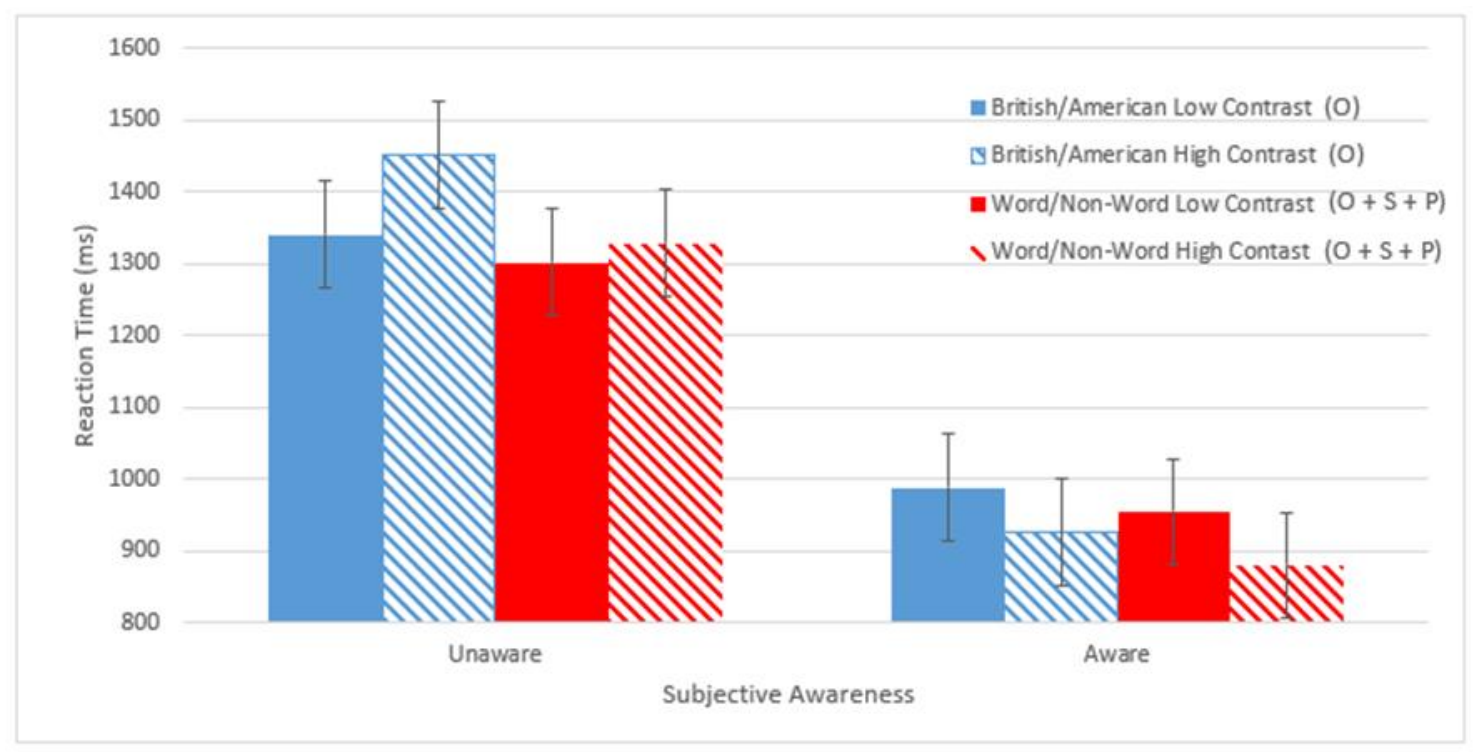

b.

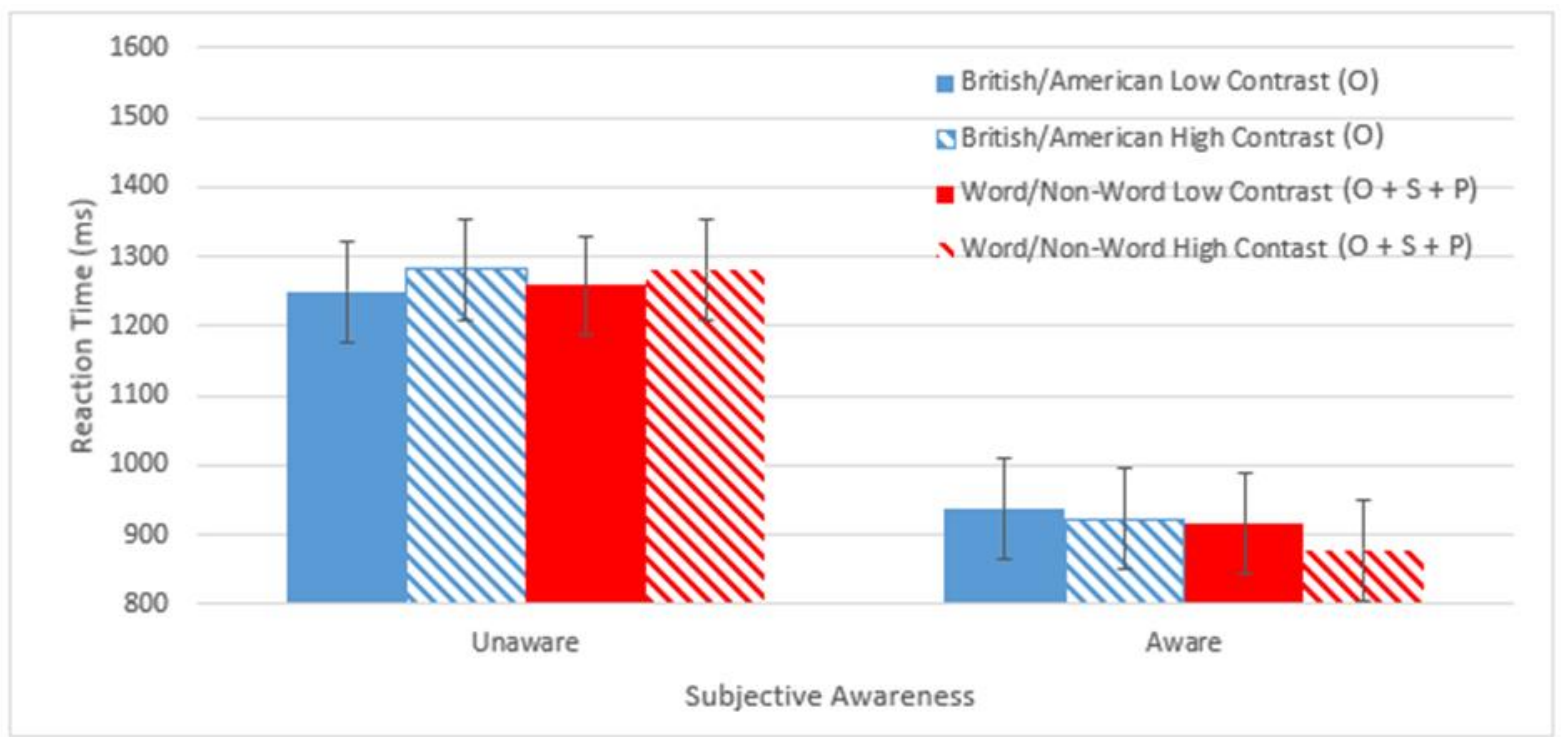

Note. The error bars represent the $95 \%$ CIs (by-subjects $\pm 74.29 \mathrm{~ms}$; by-items $\pm 72.32 \mathrm{~ms}$ ). O, S, and P stand for orthographic, semantic, and phonological differences, respectively. 


\section{Experiment 2 Discussion}

The results of Experiment 2 replicated the key findings of Experiment 1, whereby participants were more accurate and sensitive when identifying word/nonword pairs than British/American pairs, supporting the notion that the additional semantic and phonological differences that word/nonword pairs have over British/American pairs significantly aids accuracy and sensitivity performance in the 2AFC task, and that the task alone does not simply isolate orthographic processing. Further supporting this are the $95 \%$ CIs for accuracy/sensitivity in the aware condition, which illustrate that performance is better for word/nonword pairs than the British/American pairs in the matching contrast condition. The increased visibility of the high contrast condition may have allowed for additional network activation, which in turn could allow the word/nonword differences in semantics and phonology to improve performance above chance in the unaware condition relative to Experiment 1 where only the low contrast condition was included. When participants were aware of the stimuli, high quality stimuli (in the form of high stimulus contrast) were easier to identify than the low quality (low contrast) stimuli. The effect of pair type did not interact with target visibility on RT (or accuracy), therefore there is no evidence for a feedback mechanism from higher level semantics and phonology to lower level orthographic encoding in this $2 \mathrm{AFC}$ task. We note that statistical tests of additivity are problematic given that additivity between two factors reflects a null hypothesis, and statistical tests are designed to reject, not accept, null hypotheses. However, consideration of the relatively high p-values in the tests of additivity presented here, accompanied by Bayesian analyses with converging evidence, supports the interpretation of additive effects. 


\section{General Discussion}

The goal of this research was to use the 2AFC task to assess the role of orthography, semantics, and phonology in 2AFC perceptual word identification by manipulating stimulus pair type in terms of whether the pair differed in orthography only, or also in phonology or semantics. Given that word/nonword pairs differ on all three of orthography, semantics, and phonology, but British/American pairs only differ on orthography, it was expected that if information from all three systems is utilized during this $2 \mathrm{AFC}$ task, then performance should be better when participants encounter word/nonword pairs. Experiment 1 demonstrated that word/nonword pairs exhibited better accuracy and sensitivity than the British/American pairs. Experiment 2 replicated this effect, and used the additive-factors method for RT to examine whether feedback to the level of orthography was behind the improved performance of word/nonword pairs. Using a manipulation of target visibility by incorporating high and low contrast trials, Experiment 2 found that target visibility successfully affected orthographic encoding (particularly through improving accuracy and sensitivity when stimulus contrast was high), but this effect of target visibility did not interact with pair type on RT or accuracy. This lack of an interaction between target visibility and pair type on RT indicates that a feedback mechanism from semantics and phonology to orthographic encoding is likely not the process by which the effect of pair type occurs. Instead, the contributions from the semantic and phonological systems when word/nonword pairs are used could simply be part of an overall assessment of activation in the entire network, as suggested by Borowsky and Masson (1996). In other words, participants could be relying on all things that can help assess how close their network is to a familiar state when comparing the target and foil alternatives, and utilization of semantic and phonological differences clearly can contribute to such a comparison. In this case, when researchers wish to 
constrain the task demands to just an orthographic level, the use of British and American word pairs is one way to do so, as we have demonstrated here.

Along with the replication of main effects between Experiments 1 and 2, the consistency between the by-subjects/by-items ANOVAs and supplementary (G)LMM analyses lends strength to our conclusion that the $2 \mathrm{AFC}$ task with word/nonword pairs does not isolate orthographic contributions but this can be achieved by using British/American pairs. For every analysis in both experiments there was a significant effect of pair type for at least the aware conditions, and/or a significant interaction between pair type and subjective awareness on Accuracy, supporting the hypothesis that word/nonword pairs would be easier to discriminate than British/American pairs in this $2 \mathrm{AFC}$ task.

The theory of semantic feedback posited by Haro et al. (2019) can be revisited with the current results in mind. If, as Haro et al. (2019) concluded, a feedback mechanism between semantics and orthographic encoding is the process that underlies their observed effects of the semantic system on performance in the $2 \mathrm{AFC}$ task, then the target visibility manipulation of Experiment 2 should have revealed interactive effects between target visibility and pair type (in line with additive-factors logic, see also Borowsky \& Besner, 1993, 2006, and Yap et al., 2015). Rather than a continuous feedback mechanism to orthographic encoding, 2AFC task performance could be explained by orthographic processing just feeding forward, accompanied by a network monitoring process. Specifically, the network's activation for all three systems can be assessed, and a comparision between the activation from the target and the activation from the alternatives can determine the choice in perceptual identification tasks such as the 2AFC task used here (Masson \& Borowsky, 1998). Although this model of word identification has treated feedback to orthographic processing as optional depending on the task and stimuli used, other 
models such as the DRC and CDP++ treat such feedback more as a default mode (Coltheart et al., 2001; Perry et al., 2010, 2013). Ideally, all models should accommodate a controllable gradient of feedback that reflects the differing feedback effects as a function of task types and stimulus demands (e.g. Borowsky \& Besner, 1993, 2006 found evidence for feedback in lexical decision, while Yap et al. 2015 found evidence for when such feedback is absent; Borowsky \& Masson, 1996 demonstrated that replacing legal nonwords with illegal nonwords in lexical decision can be used to focus the task demands to the orthographic level; see also Yap et al. 2011 who demonstrated that word characteristics such as semantic neighborhood density have different effects depending on task type).

The research on the word superiority effect, such as Grossi et al. (2009), could also benefit from this perspective that the activation of orthography, semantics, and phonology are monitored together. Grossi et al. (2009) mentioned that word familiarity (which drives the word superiority effect) differs from orthographic familiarity (which drives the pseudoword superiority effect), but do not return to this issue, and instead focus their discussion solely on orthographic structure. Taking the other systems into account as part of a monitoring process involving the overall activation of the three systems would clarify the differences between the word superiority effect (familiar orthographic and semantic activation patterns) and pseudoword superiority effect (familiar orthographic activation patterns but no familiar semantic activation).

\section{Limitations and Future Directions}

The stimuli pairs that were used in this study are somewhat limited, as the word/nonword pairs did not allow for the separation of semantics from phonology, therefore either (or both) systems could be involved in the observed effect of pair type. Using different word stimuli in future experiments such as homophones (e.g. two and too; orthography and semantics are 
different, while phonology is the same; see Grainger \& Ferrand, 1994 and Kerswell et al., 2007, for research utilizing homophones and pseudohomophones) would separate semantics from phonology, and allow future studies to clarify whether all three systems work together, or if just one of semantics or phonology is contributing to performance in perceptual identification tasks. Future studies could include additional conditions to allow for more direct comparisons to classic word superiority paradigms. For example, word superiority effects are often based on probing which of two letters was in a particular position of a briefly presented target word, both of which would constitute a real word, but the words are typically not constrained for differences in semantics and phonology. It would be interesting to see if British/American word constraints in this paradigm would still yield a word superiority effect over nonword targets (controlled to differ only in orthography for comparability, e.g., acree vs. akree).

Another next step for this research would be the utilization of imaging techniques, such as functional magnetic resonance imaging, which could be used to compare the regions of activation for these pair type conditions in the 2AFC task. From a neuroanatomical perspective, the ventral 'what' stream (occipital-temporal regions) and the dorsal 'where/how' stream (occipital-parietal-frontal regions) of visual processing map onto reading such that lexical (i.e., word level) orthography relies primarily on the ventral stream whereas phonology is associated more so with the dorsal stream (e.g., Borowsky et al., 2006, 2007; Ekstrand et al, 2018, 2019). Processing of semantics occurs in both streams. In the 2AFC task used here, British/American pairs should primarily reveal activation differences primarily in ventral orthographic processing regions, whereas word/nonword pairs could reveal additional activation differences in dorsal phonological processing regions (see Price, 2012, for a review on imaging studies in language research). 


\section{Conclusion}

Using carefully controlled stimuli pairs in the 2AFC task, we have identified British/American word pairs are an effective way to isolate orthographic processing differences, as they do not differ on phonology and semantics as is the case when using options like word/nonword pairs, or unconstrained word pairs. Based on these results, it would be advisable for researchers to not assume that orthography will be isolated simply by using a 2AFC task. If isolation of orthography is the goal in any 2AFC study, stimuli should be carefully controlled to minimize the influence of semantics and phonology as was done here by using British/American pairs, and participants who are familiar with these variants. This research has thus improved our understanding of the mechanisms behind word perceptual identification, and provided novel data, and novel challenges, to all models of word identification. 


\section{References}

Amenta, S., Marelli, M., \& Sulpizio, S. (2017). From sound to meaning: Phonology-toSemantics mapping in visual word recognition. Psychon Bull Rev 24, 887-893. https://doi.org/10.3758/s13423-016-1152-0

Baayen, R.H., Davidson, D.J. \& Bates, D.M. (2008). Mixed-effects modeling with crossed random effects for subjects and items. Journal of Memory and Language, 59, 390-412. https://doi.org/10.1016/j.jml.2007.12.005

Balota, D.A., Yap, M.J., Cortese, M.J., Hutchison, K.A., Loftis, B., Kessler, B., Neely, J.H., Nelson, D.L., Simpson, G.B., \& Treiman, R. (2007). The English Lexicon Project. Behavior Research Methods, 39(3), 445-459. https://doi.org/10.3758/BF03193014

Bates, D., Mächler, M., Bolker, B., \& Walker, S. (2015). Fitting linear mixed-effects models using lme4. Journal of Statistical Software, 67(1), 1-48. https://doi.org/10.18637/jss.v067.i01

Aschenbrenner, A.J., Balota, D.A., Weigand, A.J., Scaltritti, M., \& Besner, D. (2017). The First Letter Position Effect in Visual Word Recognition: The Role of Spatial Attention. Journal of Experimental Psychology: Human Perception and Performance, 43(4), 700718. https://doi.org/10.1037/xhp0000342

Borowsky, R., \& Besner, D. (1993). Visual Word Recognition: A Multistage Activation Model. Journal of Experimental Psychology: Learning, Memory, and Cognition, 19 (4), 813-840. https://doi.org/10.1037/0278-7393.19.4.813

Borowsky, R., \& Besner, D. (2006). Parallel Distibuted Processing and Lexical-Semantic Effects in Visual Word Recognition: Are a Few Stages Necessary? Psychological Review, 113(1), 181-195. https://doi.org/10.1037/0033-295X.113.1.181 
Borowsky, R., Cummine, J., Owen, W.J., Friesen, C.K., Shih, F., \& Sarty, G.E. (2006). FMRI of Ventral and Dorsal Processing Streams in Basic Reading Processes: Insular Sensitivity to Phonology. Brain Topography, 18 (4), 233-239. https://doi.org/10.1007/s10548-0060001-2.

Borowsky, R., Esopenko, C., Cummine, J., Sarty, G.E. (2007). Neural Representations of Visual Words and Objects: A Functional MRI Study on the Modularity of Reading and Object Processing. Brain Topography, 20, 89-96. https://doi.org/10.1007/s10548-007-0034-1

Borowsky, R., \& Masson, M.E.J. (1996). Semantic Ambiguity Effects in Word Identification. Journal of Experimental Psychology: Learning, Memory, and Cognition, 22 (1), 63-85.

Cheesman, J., \& Merikle, P.M. (1986). Distinguishing Conscious from Unconscious Perceptual Processes. Canadian Journal of Psychology 40 (4), 343-367. https://doi.org/10.1037/h0080103

Coltheart, M., Rastle, K., Perry, C., Langdon, R., \& Ziegler, J. (2001). DRC: A Dual Route Cascaded Model of Visual Word Recognition and Reading Aloud. Psychological Review, 108(1), 204-256. https://doi.org/10.1037//0033-295X.108.1.204

Donaldson, W. (1992). Measuring recognition memory. Journal of Experimental Psychology: General, 121(3), 275-277. https://doi.org/10.1037/0096-3445.121.3.275

Donaldson, W. (1996). The role of decision processes in remembering and knowing. Memory \& Cognition, 24(4), 523-533. https://doi.org/10.3758/BF03200940

Fodor, J.A. (1983). The modularity of mind. MIT Press.

Grainger, J., \& Ferrand, L. (1994). Phonology and Orthography in Visual Word Recognition: Effects of Masked Homophone Primes. Journal of Memory and Language, 33, 218-233. Grainger, J., Bouttevin, S., Truc, C., Bastien, M., \& Ziegler, J. (2003). Word superiority, 
pseudoword superiority, and learning to read: A comparison of dyslexic and normal readers. Brain and Language, 87, 432-440. https://doi.org/10.1016/S0093$934 X(03) 00145-7$

Grossi, G., Murphy, J., Boggan, J. (2009). Word and pseudoword superiority effects in ItalianEnglish bilinguals. Bilingualism: Language and Cognition, 12(1), 113-120. https://doi.org/10.1017/S1366728908003891

Haase, S.J., \& Fisk, G.D. (2011). A Comparison of Signal Detection Theory to the Objective Threshold/Strategic Model of Unconscious Perception. Perceptual and Motor Skills, 113 (1), 242-256. https://doi.org/10.2466/22.24.27.PMS.113.4.242-256

Haro, J., Comesaña, M., \& Ferré, P. (2019). Is There an Orthographic Boost for Ambiguous Words During Their Processing? Journal of Psycholinguistic Research, 48(2), 519-534. https://doi.org/10.1007/s10936-018-9616-1Hino, Y., \& Lupker, S.J. (1996). Effects of Polysemy in Lexical Decision and Naming: An Alternative to Lexical Access Accounts. Journal of Experimental Psychology: Human Perception and Performance, 22(6), 13311356.

Kerswell, L., Siakaluk, P.D., Pexman, P.M., Sears, C.R., \& Owen, W.J. (2007). Homophone Effects in Visual Word Recognition Depend on Homophone Type and Task Demands. Canadian Journal of Experimental Psychology, 61(4), 322-327. https://doi.org/10.1037/cjep2007032

Kress, S., Neudorf, J., Ekstrand, C., \& Borowsky, R. (2020). Data for: Unmasking the Effects of Orthography, Semantics, and Phonology on 2AFC Visual Word Perceptual Identification (Version 1.0) [Data set]. Zenodo. https://doi.org/10.5281/zenodo.3990549

Lorentz, E., Gould, L., Mickleborough, M., Ekstrand, C., Boyer, M., Cheesman, J., \& Borowsky, 
R. (2015). All in One Fell Stroop: Examining Consciousness Thresholds With a Multiple Response Paradigm. Psychology of Consciousness: Theory, Research, and Practice, 2 (2), 111-133. https://doi.org/10.1037/cns0000049

Lorentz, E., McKibben, T., Ekstrand, C., Gould, G., Anton, K., \& Borowsky, R. (2016). Disentangling Genuine Semantic Stroop Effects in Reading from Contingency Effects: On the Need for Two Neutral Baselines. Frontiers in Psychology, 7 (386). https://doi.org/10.3389/fpsyg.2016.00386

Loftus, G.R., \& Masson, M.E.J. (1994). Using confidence intervals in within-subjects designs. Psychonomic Bulletin \& Review, 1 (4), 476-490. https://doi.org/10.3758/BF03210951

Manelis, L. (1974). The effect of meaningfulness in tachistoscopic word perception. Perception \& Psychophysics, 16 (1), 182-192. https://doi.org/10.3758/BF03203272

Marcel, A.J. (1983). Conscious and Unconscious Perception: Experiments on Visual Masking and Word Recognition. Cognitive Psychology, 15, 197-237. https://doi.org/10.1016/00100285(83)90009-9

Marelli, M., \& Amenta, S. (2018). A database of orthography-semantics consistency (OSC) estimates for 15,017 English words. Behavior Research Methods 50, 1482-1495. https://doi.org/10.3758/s13428-018-1017-8

Masson, M.E.J. (2011). A tutorial on a practical Bayesian alternative to null-hypothesis significance testing. Behavioural Research, 43, 679-690. https://doi.org/10.3758/s13428010-0049-5

Masson, M.E.J., \& Borowsky, R. (1998). More than meets the eye: Context effects in word identification. Memory \& Cognition, 26 (6), 1245-1269. https://doi.org/10.3758/BF03201198 
Matuschek, H., Kliegl, R., Vasishth, S., Baayen, H., \& Bates, D. (2017). Balancing Type I error and power in linear mixed models. Journal of Memory and Language, 94, 305-315. https://doi.org/10.1016/j.jml.2017.01.001

Perry, C., Ziegler, J.C., \& Zorzi, M. (2010). Beyond single syllables: Large-scale modeling of reading aloud with the Connectionist Dual Process $(\mathrm{CDP}++)$ model. Cognitive Psychology, 61, 106-151. https://doi.org/10.1016/j.cogpsych.2010.04.001

Perry, C., Ziegler, J.C., \& Zorzi, M. (2013). A Computational and Empirical Investigation of Graphemes in Reading. Cognitive Science, 1-29. https://doi.org/10.1111/cogs.12030

Price, C.J. (2012). A review and synthesis of the first 20 years of PET and fMRI studies of heard speech, spoken language and reading. NeuroImage, 62, 816-847. https://doi.org/10.1016/j.neuroimage.2012.04.062

R Core Team (2018). R: A language and environment for statistical computing. Vienna, Austria: R Foundation for Statistical Computing. https://www.R-project.org/.

Reicher, G.M. (1969). Perceputal recognition as a function of meaningfulness of stimulus material. Journal of Experimental Psychology, 81(2), 275-280.

Rouder, J.N., Speckman, P.L., Sun, D., Morey, R.D., and Iverson, G. (2009). Bayesian t tests for accepting and rejecting the null hypothesis. Psychonomic Bulletin \& Review, 16(2), 225237. https://doi.org/10.3758/PBR.16.2.225

Scaltritti, M., \& Balota, D.A. (2013). Are all letters really processed equally and in parallel? Further evidence of a robust first letter advantage. Acta Psychologica, 144, 397-410. https://doi.org/10.1016/j.actpsy.2013.07.018

Stanislaw, H., \& Todorov, N. (1999). Calculation of signal detection theory measures. Behavior Research Methods, Instruments, \& Computers, 31(1), 137-149. 
https://doi.org/10.3758/BF03207704

Sternberg, S. (1969). The Discovery of Processing Stages: Extensions of Donders' Method. Acta Psychologica Attention and Performance II, 30, 276-315.

Wheeler, D.D. (1970). Processes in Word Recognition. Cognitive Psychology, 1, 59-85.

Wingerak, S., Neudorf, J., Gould, L., \& Borowsky, R. (2017). On the dissociation between reaction time and response duration as a function of lexical and sublexical reading: An examination of phonetic decoding and computational models. Visual Cognition, 25, 913927. https://doi.org/10.1080/13506285.2017.1352640

Yap, M.J., Lim, G.Y., Pexman, P.M. (2015). Semantic richness effects in lexical decision: The role of feedback. Memory \& Cognition, 43, 1148-1167. https://doi.org/10.3758/s13421015-0536-0

Yap, M.J., Tan, S.E., Pexman, P.M., \& Hargreaves, I.S. (2011). Is more always better? Effects fo semantic richness on lexical decision, speeded pronunciation, and semantic classification. Psychonomic Bulletin \& Review, 18, 742-750. https://doi.org/10.3758/s13423-011-0092$\mathrm{y}$ 


\section{Appendix A}

Stimulus Word/Nonword List with Summed Bigram Frequency

\begin{tabular}{|c|c|c|c|c|c|c|c|}
\hline $\begin{array}{l}\text { British } \\
\text { Word }\end{array}$ & $\begin{array}{l}\text { Sum } \\
\text { BF }\end{array}$ & $\begin{array}{l}\text { American } \\
\text { Word }\end{array}$ & $\begin{array}{l}\text { Sum } \\
\text { BF }\end{array}$ & $\begin{array}{l}\text { British } \\
\text { Nonword }\end{array}$ & $\begin{array}{l}\text { Sum } \\
\text { BF }\end{array}$ & $\begin{array}{ll}\text { American } & \text { Sum } \\
\text { Nonword } & \mathrm{BF}\end{array}$ & $\begin{array}{l}\text { Counter } \\
\text { Balance } \\
\text { Group }\end{array}$ \\
\hline analyse & 24443 & analyze & 21024 & analyme & 23530 & same as British & 2 \\
\hline centre & 26892 & center & 36989 & cenkre & 18956 & cenker & 1 \\
\hline cosy & 7074 & cozy & 4838 & comy & 7146 & same as British & 2 \\
\hline defence & 19278 & defense & 22210 & defenve & 17898 & same as British & 1 \\
\hline $\operatorname{disc}$ & 11179 & disk & 9842 & disb & 9468 & same as British & 2 \\
\hline fibre & 11917 & fiber & 17495 & fidre & 12293 & 21241 & 2 \\
\hline grey & 10320 & gray & 8349 & gruy & 2868 & same as British & 1 \\
\hline kilometre & 27441 & kilometer & 37538 & kikometre & 21846 & kikometer & 1 \\
\hline licence & 25328 & license & 28260 & licende & 28220 & same as British & 1 \\
\hline litre & 21473 & liter & 31570 & lilre & 17188 & 28629 & 2 \\
\hline mum & 2190 & mom & 4215 & $\operatorname{mim}$ & 4505 & same as British & 1 \\
\hline meagre & 17788 & meager & 23539 & meapre & 18867 & meaper & 2 \\
\hline offence & 14802 & offense & 17734 & offenfe & 11253 & same as British & 2 \\
\hline paralyse & 28590 & paralyze & 25171 & paralyne & 29423 & same as British & 2 \\
\hline practise & 31972 & practice & 29553 & practife & 24532 & same as British & 2 \\
\hline pretence & 34650 & pretense & 37582 & pretenge & 40474 & same as British & 1 \\
\hline pyjamas & 8967 & pajamas & 11045 & pojamas & 10975 & same as British & 1 \\
\hline sabre & 13057 & saber & 18635 & satre & 21420 & 31517 & 1 \\
\hline
\end{tabular}




\begin{tabular}{|c|c|c|c|c|c|c|c|c|}
\hline theatre & 29019 & theater & 39116 & thealre & 23414 & thealer & 34855 & 2 \\
\hline tyre & 9540 & tire & 19155 & tyce & 4032 & tice & 16422 & 1 \\
\hline \multicolumn{9}{|c|}{$\underline{\text { Practice Trial Stimuli }}$} \\
\hline artefact & 22939 & artifact & 23792 & artefast & 28842 & artifast & 29695 & N/A \\
\hline cypher & 18523 & cipher & 20852 & cyphet & 8362 & ciphet & 10691 & N/A \\
\hline kerb & 15530 & curb & 4675 & berb & 15642 & burb & 4506 & N/A \\
\hline mollusc & 14695 & mollusk & 13358 & mollusp & 14398 & \multicolumn{2}{|c|}{ same as British } & N/A \\
\hline sceptic & 20138 & skeptic & 17872 & sneptic & 21291 & \multicolumn{2}{|c|}{ same as British } & N/A \\
\hline vender & 31896 & vendor & 20267 & venfer & 25455 & venfor & 17505 & N/A \\
\hline
\end{tabular}




\section{Appendix B}

Counter Balance Technique for the Word/Nonword Block

\begin{tabular}{|l|l|l|l|}
\hline Participant Number & $\mathbf{2 7}$ ms & $\mathbf{4 0} \mathbf{~ m s}$ & $\mathbf{5 3} \mathbf{~ m s}$ \\
\hline 1 & Group 1 & Group 1 & Group 2 \\
\hline 2 & Group 1 & Group 2 & Group 1 \\
\hline 3 & Group 1 & Group 2 & Group 2 \\
\hline 4 & Group 2 & Group 1 & Group 1 \\
\hline 5 & Group 2 & Group 1 & Group 2 \\
\hline 6 & Group 2 & Group 2 & Group 1 \\
\hline
\end{tabular}

This illustrates which word/nonword set was presented with the British spelling. The opposite group of words would be presented with the American spelling (see Appendix A for the Group 1/Group 2 assignments). Note that $27 \mathrm{~ms}$ trials were excluded from analysis in Experiment 1 and never included in the design Experiment 2, therefore the trials utilized in analysis follow the counterbalance rules of the $40 \mathrm{~ms}$ and $53 \mathrm{~ms}$ columns. 


\section{Appendix C}

\section{Supplementary General and Linear Mixed Model Analyses}

\section{Experiment 1}

\section{General Linear Mixed Model Analysis}

To conduct the GLMM analysis, the glmer function from the lme4 package (version 1.121; Bates et al., 2015) in R (version 3.5.1; R Core Team, 2018) was used. During the later RT analysis, thirty-one outlier trials were excluded. These trials were also excluded from the accuracy data set to maintain consistency between accuracy and RT analyses. Therefore, the GLMM for accuracy includes 3649 trials $(99.16 \%$ of the data).

The initial maximal model included pair type and awareness as fixed effects, as well as the interaction between the two. Random intercepts for both items and subjects were also included in this model, with the fixed effects and interaction included as random slopes. This maximal model did not converge, so the random slopes with the least variance were removed until the model converged. From this converging model, a more parsimonious model was found using a likelihood-ratio test (LRT) with $\alpha=0.20$ (see Matuscheck et al., 2017). Z-values greater than 2.0 indicate significant effects (e.g., Baayen et al., 2008). There was a significant main effect of awareness, performance was worse during unaware trials than aware trials, Estimate = $0.53, S E=0.12, z=-3.90$. There was also a main effect of pair type, accuracy was higher for word/nonword pairs than for British/American pairs, Estimate $=0.43, S E=0.16, z=2.66$. Finally, the Awareness $\times$ Pair Type interaction was significant, Estimate $=-0.45, S E=0.16, z=-$ 2.77. These results are outlined in Table $\mathrm{C} 1$. 


\section{Table C1}

General Linear Mixed Model of Experiment 1 Accuracy as a function of Pair Type and

Subjective Awareness

\begin{tabular}{|c|c|c|c|}
\hline \multirow[b]{2}{*}{ Random effects } & \multicolumn{3}{|c|}{ Accuracy } \\
\hline & Variance & & SD \\
\hline \multicolumn{4}{|l|}{ Subjects } \\
\hline Intercept & 0.02 & & 0.14 \\
\hline \multicolumn{4}{|l|}{ Items } \\
\hline Intercept & 0.18 & & 0.42 \\
\hline Awareness & 0.15 & & 0.39 \\
\hline Pair Type & 0.29 & & 0.54 \\
\hline Awareness x Pair Type & 0.09 & & 0.31 \\
\hline Fixed Effects & Estimate & Std. Error & z-value \\
\hline Intercept & 0.65 & 0.12 & 5.26 \\
\hline Awareness (Unaware- Aware) & -0.53 & 0.13 & $-3.90 *$ \\
\hline Pair Type (Word/Nonword - British/American) & 0.43 & 0.16 & $2.66^{*}$ \\
\hline Awareness $\times$ Pair Type & -0.45 & 0.16 & $-2.77 *$ \\
\hline
\end{tabular}

Note. An asterisk indicates significant results $(|z|>2.00)$. 


\section{Linear Mixed Model Analysis}

The lmer function from the lme4 package (version 1.1-21; Bates et al., 2015) in $\mathrm{R}$ (version 3.5.1; R Core Team, 2018) was used to conduct the LMM analysis on the RT of correct trials. Prior to this RT analysis, thirty-one trials were excluded, as the RTs of these trials were more than three standard deviations outside the mean. Therefore, the LMM for RT includes 2251 trials $(98.64 \%$ of the data).

The maximal model for RT included pair type and awareness as fixed effects, as well as the Subjective Awareness $\times$ Pair Type interaction. Random intercepts for both items and subjects were also included in this model, with the fixed effects and interaction included as random slopes. A more parsimonious model could not be found using the likelihood-ratio test (LRT) with $\alpha=0.20$ (see Matuscheck et al., 2017), so the maximal model was used for the LMM analysis. T-values greater than 2.0 indicate significant effects (e.g., Baayen et al., 2008). There was a significant main effect of subjective awareness, RTs were slower during unaware trials than aware trials, Estimate $=185.25, S E=71.04, t=2.61$. The other main effect and interaction were not significant, as summarized in Table C2. The results of all analyses are summarized in Table C3.

\section{Table C2}

Linear Mixed Model for Experiment 1 RT as a function of Pair Type and Subjective Awareness

\begin{tabular}{lll}
\hline \multirow{2}{*}{ Random effects } & \multicolumn{2}{c}{ Reaction Time } \\
\cline { 3 - 3 } Subjects & Variance & SD \\
Intercept & 41875 & 204.63 \\
Awareness & 63736 & 252.46
\end{tabular}


Pair Type

29251

171.03

Awareness x Pair Type

33410

182.79

Items

Intercept

20075

141.69

Awareness

26113

161.60

Pair Type

3851

62.06

Awareness x Pair Type

20046

141.58

Residual

205790

453.64

\begin{tabular}{lccc}
\hline Fixed Effects & Estimate & Std. Error & t-value \\
\hline Intercept & 1221.98 & 57.02 & 21.43 \\
Awareness (Unaware - Aware) & 185.25 & 71.04 & $2.61^{*}$ \\
Pair Type (Word/Nonword - British/American) & -42.71 & 46.50 & -0.92 \\
Awareness x Pair Type & 111.67 & 65.28 & 1.71
\end{tabular}

Note. An asterisk indicates significant results $(|\mathrm{t}|>2.00)$. 


\section{Table C3}

Summary of main effects and interactions from all Experiment 1 analyses.

\begin{tabular}{llll}
\hline $\begin{array}{l}\text { Accuracy } \\
\text { Main Effects }\end{array}$ & By Subjects & By Items & GLMM \\
$\begin{array}{l}\text { Pair Type } \\
\text { Subjective Awareness }\end{array}$ & $F=3.45$ & $F=3.18$ & $z=2.66^{*}$ \\
Interactions & $F=100.49^{*}$ & $F=41.86^{*}$ & $z=-3.90^{*}$ \\
Pair Type $\times$ Subjective Awareness & $F=8.46^{*}$ & $F=9.51^{*}$ & $z=-2.77^{*}$ \\
\hline $\begin{array}{l}\text { Reaction Time } \\
\text { Main Effects }\end{array}$ & By Subjects & By Items & LMM \\
$\begin{array}{l}\text { Pair Type } \\
\text { Subjective Awareness }\end{array}$ & $\mathrm{F}=0.10$ & $\mathrm{~F}=0.06$ & $\mathrm{t}=-0.92$ \\
$\begin{array}{l}\text { Interactions } \\
\text { Pair Type } \times \text { Subjective Awareness }\end{array}$ & $\mathrm{F}=17.46^{*}$ & $\mathrm{~F}=44.63^{*}$ & $\mathrm{t}=2.61^{*}$ \\
\hline
\end{tabular}

Note. An asterisk indicates significant results based on the analyses reported in text.

\section{Experiment 2}

\section{General Linear Mixed Model Analysis}

The same procedure and programs to conduct the GLMM analysis from Experiment 1 were used for Experiment 2. In this case, during RT analysis, ninety-nine outlier trials were excluded (see Experiment 2's RT LMM for more details). To maintain consistency between the GLMM and LMM, these trials were also excluded from this accuracy analysis. Therefore, the GLMM for accuracy includes 7581 trials $(98.71 \%$ of the data).

The initial maximal model included pair type, awareness, and target visibility as fixed effects, as well as the interactions between the three. Random intercepts for both items and subjects were also included in this model, with the fixed effects and interactions included as 
random slopes. Random slopes with the least variance were then removed until the model converged, as the initial maximal model was non-converging. The converging model was the minimal model, so there was no need to find a more parsimonious model. There was a significant main effect of awareness, replicating the first experiment, accuracy was lower for trials in which participants indicated that they were guessing than when they were not guessing, Estimate = $0.5565, S E=0.12, z=-4.76$. There was also a main effect of pair type, again replicating the earlier results. Accuracy was higher for word/nonword pairs than for British/American pairs, Estimate $=0.43, S E=0.14, z=3.22$. The main effect of target visibility was significant, accuracy was higher for high contrast trials than for low contrast trials, Estimate $=0.68, S E=0$. $12, z=5.68$. Finally, there was a significant Awareness $\times$ Target Visibility interaction, Estimate $=-0.41, S E=0.16, z=-2.48$. The other interactions were not significant and are summarized in Table C4. 


\section{Table C4}

General linear mixed model for Experiment 2 Accuracy as a function of Pair Type, Target Visibility, and Subjective Awareness

\begin{tabular}{|c|c|c|c|}
\hline \multirow[b]{2}{*}{ Random effects } & \multicolumn{3}{|c|}{ Accuracy } \\
\hline & Variance & & SD \\
\hline \multicolumn{4}{|l|}{ Subjects } \\
\hline Intercept & 0.21 & & 0.45 \\
\hline \multicolumn{4}{|l|}{ Items } \\
\hline Intercept & 0.29 & & 0.54 \\
\hline Fixed Effects & Estimate & Std. Error & z-value \\
\hline Intercept & 0.85 & 0.18 & 4.67 \\
\hline Awareness (Unaware - Aware) & -0.56 & 0.12 & $-4.76^{*}$ \\
\hline Pair Type (Word/Nonword - British/American) & 0.43 & 0.14 & $3.22 *$ \\
\hline Target Visibility (High Contrast - Low Contrast) & 0.68 & 0.12 & $5.68^{*}$ \\
\hline Awareness $\times$ Pair Type & -0.14 & 0.16 & -0.90 \\
\hline Awareness $\times$ Target Visibility & -0.41 & 0.16 & $-2.48 *$ \\
\hline Pair Type $\times$ Target Visibility & 0.24 & 0.17 & 1.38 \\
\hline Awareness $\times$ Pair Type $\times$ Target Visibility & -0.48 & 0.24 & -1.97 \\
\hline
\end{tabular}

Note. An asterisk indicates significant results $(|\mathrm{z}|>2.00)$.

\section{Linear Mixed Model Analysis}

The same procedure and packages that were used in Experiment 1 were also used to conduct the LMM analysis on the RT of correct trials for Experiment 2. Before analyzing the data, ninety-nine trials were excluded from analysis, as the RTs of these trials were greater than three standard deviations from the mean. The LMM for RT includes 2251 trials $(98.21 \%$ of the data).

For this analysis, the maximal model included pair type, awareness, and target visibility 
as fixed effects, as well as the interactions between these fixed effects. The random intercepts for both items and subjects were also included in this model, as well as random slopes of the fixed effects and interactions. This maximal model did not converge, therefore, the random slopes with the least variance were removed until a converging model was achieved. Models that were more parsimonious did not pass the likelihood-ratio test (LRT) with $\alpha=0.20$ (see Matuscheck et al., 2017), so the converging model was used for the LMM analysis. Replicating the previous analyses, there was a significant main effect of awareness, RTs were slower when participants indicated that they were unaware of the stimuli than when they were aware of the stimuli, Estimate $=213.00, S E=68.30, t=3.12$. There was also a main effect of target visibility, RTs were faster during high contrast trials than low contrast trials, Estimate $=-125.38, S E=27.17, t$ $=-4.62$. Finally, the interaction between awareness and target visibility was significant, Estimate $=175.38, S E=58.53, t=3.00$. Table C5 summarizes the results of the LMM, and includes the values of the other main effects and interactions, which were not significant. Table C6 summarizes the results of all analyses for Experiment 2. 


\section{Table C5}

LMM results for Experiment 2 RT as a function of Pair Type, Target Visibility, and Subjective Awareness.

\begin{tabular}{|c|c|c|c|}
\hline \multirow[b]{2}{*}{ Random effects } & \multicolumn{3}{|c|}{ Reaction Time } \\
\hline & Variance & & SD \\
\hline \multicolumn{4}{|l|}{ Subjects } \\
\hline Intercept & 85366 & & 292.17 \\
\hline Awareness & 80533 & & 283.78 \\
\hline Pair Type & 38264 & & 195.61 \\
\hline Target Visibility & 6578 & & 81.11 \\
\hline Awareness x Pair Type & 46573 & & 215.81 \\
\hline Awareness $\mathrm{x}$ Target Visibility & 53390 & & 231.06 \\
\hline Pair Type x Target Visibility & 6378 & & 79.86 \\
\hline Awareness x Pair Type x Target Visibility & 54106 & & 232.61 \\
\hline \multicolumn{4}{|l|}{ Items } \\
\hline Intercept & 18416 & & 135.71 \\
\hline Awareness & 14026 & & 118.43 \\
\hline Pair Type & 3054 & & 55.26 \\
\hline Awareness x Pair Type & 3963 & & 62.95 \\
\hline Residual & 132480 & & 363.98 \\
\hline Fixed Effects & Estimate & Std. Error & t-value \\
\hline Intercept & 1137.91 & 69.67 & $16.33 *$ \\
\hline Awareness (Unaware - Aware) & 213.00 & 68.30 & $3.12 *$ \\
\hline Pair Type (Word/Nonword - British/American) & -93.43 & 48.56 & -1.92 \\
\hline Target Visibility (High Contrast - Low Contrast) & -125.38 & 27.17 & $-4.62 *$ \\
\hline Awareness x Pair Type & 75.77 & 56.88 & 1.33 \\
\hline Awareness $\mathrm{x}$ Target Visibility & 175.38 & 58.53 & $3.00 *$ \\
\hline Pair Type x Target Visibility & 42.14 & 32.56 & 1.29 \\
\hline Awareness x Pair Type x Target Visibility & -73.10 & 69.57 & -1.05 \\
\hline
\end{tabular}

Note. An asterisk indicates significant results $(|t|>2.00)$. 


\section{Table C6}

Summary of main effects and interactions from Experiment 2 analyses.

\begin{tabular}{|c|c|c|c|}
\hline Accuracy & By Subjects & By Items & GLMM \\
\hline \multicolumn{4}{|l|}{ Main Effects } \\
\hline Pair Type & $F=5.30^{*}$ & $F=24.90^{*}$ & $z=3.22 *$ \\
\hline Subjective Awareness & $F=170.64^{*}$ & $F=69.93^{*}$ & $z=-4.76^{*}$ \\
\hline Target Visibility & $F=10.34^{*}$ & $F=8.75^{*}$ & $z=5.68^{*}$ \\
\hline \multicolumn{4}{|l|}{ Interactions } \\
\hline Pair Type $\times$ Subjective Awareness & $F=1.27$ & $F=19.36^{*}$ & $z=-0.90$ \\
\hline Pair Type $\times$ Target Visibility & $F=0.04$ & $F=0.66$ & $z=1.38$ \\
\hline Subjective Awareness $\times$ Target Visibility & $F=9.70^{*}$ & $F=3.44$ & $z=-2.48^{*}$ \\
\hline \multicolumn{4}{|l|}{ Pair Type $\times$ Subjective Awareness $\times$ Target } \\
\hline Visibility & $F=1.84$ & $F=0.34$ & $z=-1.97$ \\
\hline Reaction Time & By Subjects & By Items & LMM \\
\hline \multicolumn{4}{|l|}{ Main Effects } \\
\hline Pair Type & $F=1.40$ & $F=0.21$ & $t=-1.92$ \\
\hline Subjective Awareness & $F=58.56^{*}$ & $F=167.30^{*}$ & $t=3.12 *$ \\
\hline Target Visibility & $F=0.000$ & $F=0.001$ & $t=-4.62 *$ \\
\hline \multicolumn{4}{|l|}{ Interactions } \\
\hline Pair Type $\times$ Subjective Awareness & $F=0.52$ & $F=1.02$ & $t=1.33$ \\
\hline Pair Type $\times$ Target Visibility & $F=1.06$ & $F=0.15$ & $t=1.29$ \\
\hline Subjective Awareness $\times$ Target Visibility & $F=2.78$ & $F=1.28$ & $t=3.00 *$ \\
\hline \multicolumn{4}{|l|}{ Pair Type $\times$ Subjective Awareness $\times$} \\
\hline Target Visibility & $F=0.49$ & $F=0.02$ & $t=-1.05$ \\
\hline
\end{tabular}

Note. An asterisk indicates significant results based on the analyses reported in text. 


\section{Subset Linear Mixed Model Analysis}

An LMM analysis was conducted on the subset of subjects and items which had both an effect of Contrast (High Contrast condition faster than Low Contrast condition) and an effect of Pair Type (Word/Nonword condition faster than British/American condition) when participants were not guessing (i.e., Aware trials). Of the 24 subjects, 10 were included, and of the 20 items, 8 were included, for a total of 726 observations. Following the recommendations of Matuschek et al. (2017), the maximal model was systematically reduced by removing random slopes with the least variance. The most parsimonious model that still passed the LRT with $\alpha=0.20$ was used for the LMM analysis. In this case, the most parsimonious model included the fixed effects of Pair Type, Target Visibility, and Pair Type $\times$ Target Visibility, in addition to the random intercepts for subjects and items, and the random slope for Subject $\times$ Pair Type. The results of this analysis indicate significant effects of Pair Type and Target Visibility, but no significant Pair Type $\times$ Target Visibility interaction (see Table C7) 


\section{Table C7}

\begin{tabular}{lccc}
\hline & \multicolumn{2}{c}{ Reaction Time } \\
\cline { 2 - 4 } Random effects & Variance & \multicolumn{1}{c}{$S D$} \\
\hline Subjects & 103618 & 321.9 \\
Intercept & 29107 & 170.6 \\
Pair Type & & \\
Items & 27828 & 166.8 \\
Intercept & 169085 & 411.2 \\
Residual & Estimate & Std. Error & $t$-value \\
\hline Fixed Effects & 1362.00 & 124.82 & $10.91^{*}$ \\
\hline Intercept & -238.68 & 49.65 & $-4.81^{*}$ \\
Pair Type (Word/Nonword - British/American) & -295.21 & 76.04 & $-3.88^{*}$ \\
Target Visibility (High Contrast - Low Contrast) & 62.90 & 65.33 & 0.96 \\
Pair Type x Target Visibility & & & \\
\end{tabular}

Note. An asterisk indicates significant results $(|t|>2.00)$. 